\title{
REVUE
}

\section{Études sur les pâturages et les aliments du bétail dans les pays tropicaux et subtropicaux}

(fin)

par M.-G. CURASSON

\section{COMPLÉMENTS}

Cette Revue, où nous nous sommes efforcés de donner l'essentiel des acquisitions concernant le sujet, s'est étalée sur quatre années de notre publication. Il est apparu nécessaire de condenser, en ces compléments, ce qui entre temps avait paru dans la littérature spécialisée.

Nous employons pour cela le mode de présentation primitivement adopté.

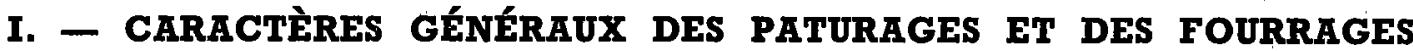

A Madagascar, la Conférence consultative de l'Elevage a fixé à 5 ha la charge optima des pâturages par « unité-bétail ».

Trois foins de même composition (taff et Setaria digitaria) récoltés à Magascar ont respectivement la composition suivante:

\begin{tabular}{|c|c|c|c|}
\hline & 1 & 2 & 3 \\
\hline Eau & 12,30 & 12,20 & 11,92 \\
\hline Protides & 5,37 & 5,50 & 6,70 \\
\hline Lipides . . . . . . . . . & 0,64 & 1,00 & 0,78 \\
\hline Cellulose .. & 33,78 & 36 & 35,5 \\
\hline Glucides ........... & 41,97 & 35,78 & 38,6 \\
\hline Cendres .......... & 5,94 & 6,52 & 6,44 \\
\hline Calcium (mg p. $100 \mathrm{~g}$ ) & 189,8 & 358,2 & 522,6 \\
\hline Phosphore ..... & 16,4 & 42,6 & 74,8 \\
\hline
\end{tabular}

Les foins obtenus dans l'Inde pendant la mousson perdent 40 p. 100 de leurs protéines digestibles, alors que la perte n'est que de 20 p. 100 , pendant la belle saison; si on sèche sous hangar pendant la mousson on perd seulement 12 p. 100 .

Sur le plateau central du Tanganyika, l'analyse des foins obtenus avec les principales graminées montre que la plus forte teneur en protćine est celle d'une première coupe de Cynodon leptostachyum, 9,6 p. 100 sur la matière sèche, la deuxième coupe ne donnant plus que 7,31 p. 100 . Comparativement, d'autres espèces donnent les pourcentages suivanls en protéine brute (pour 100 de matiere sèche).

\begin{tabular}{|c|c|}
\hline 'Andropogon caricossus...... & 6,12 \\
\hline Cenchrus ciliaris.. & 6,89 à 7,42 \\
\hline Chloris gayana ...... & 3,70 \\
\hline Digitaria pentzii & 7,52 \\
\hline Panicum maximum & 8,86 \\
\hline Pennisetum purpureum & 8,07 \\
\hline
\end{tabular}

Chez toutes les plantes fourragères cultivées, graminées et légumineuses, on constate en général un accroissement de l'acide glutamique et de l'acide aspartique et une diminution de la lysine et de l'arginine quand se forme la graine; la premiere pousse contient plus de leucine et d'arginine que la seconde et moins d'acide glutamique.

De façon générale, les engrais azotés diminuent l'acide aspartique et l'acide glutamique et accroissent leucine, phénylalanine, arginine, lysine et tryptophane.

Les essais faits avec des graminées de l'Inde, Iseilema laxum, Amphilophis odorata et A. glabra, montrent que dans ces plantes les protéines, l'extrait 
éthéré, les minéraux solubles, $\mathrm{P}_{2} \mathrm{O}_{5}, \mathrm{Na}, \mathrm{K}$ et $\mathrm{Cl}_{1}$ diminuent alors que la cellulose augmente avec le degré de maturité. L'extractif non azoté varie irrégulièrement mais tend à baisser. Pour les Amphilophis, le rapport $\mathrm{Ca} / \mathrm{P}$ est plus favorable au stade jeune, alors que pour I. laxum, c'est au moment de la floraison.
Less essais réalisés dans l'Est africain avec trois graminées Prothriochloa insculpta, Chloris gayana et Brachiaria dictyoneura, montrent que la teneur en protéine et en phosphore est liée à la pluie.

De façon générale, les protéines des feuilles sont assez pauvresi en méthionine; les autres amino-' acides sont mieux représentés.

\section{II. - CAUSES D'ALtÉRATION DES PATURAGES}

L'influence des termites sur les pâturages de brousse a été déterminée en Afrique du \$ud. En général, ces insectes, et particulièrement les termites phytophages, les seuls qui se nourrissent de végétaux vivants, auraient un rôle dans le maintien de la fertilité des sols et devraient être protéges, sauf cependant une exception très importante, dans les régions où l'équilibre naturel a été supprimé par la surpécoration du veld; alors, la capacité de détérioration des termites l'emporte sur leur influence bénéfique.

Dans ces régions dénudées ou ne portant plus qu'une végétation désertique, il faut envisager la destruction des termites phytophages. La campagne entreprise dans le Zululand est basée sur l'emploi, sur une grande échelle, de foin ou de paille empoisonnés par une solution de fluosilicate "de soude.

En A.E.F., d'après les essais qui ont été faits dans la vallée du Niari, le pacage des animaux modifie très sensiblemont la formo et la composition dos herbages. Les graminées pérennes tendent à recouvrir entièrement le sol, la densité des espèces rampantes comme Schizachyrium platiphyllum et des graminées annuelles, augmente :

- de 120 p. 100 par rapport à la savane intacte jamais pâturée, sur une zone de collines pacagées depuis 1 an;

-de 80 p. 100 sur des terrasses alluvio-colluviales ;

- de 20 p. 100 sur des collines caillouteuses;

- de 40 p. 100 dans des fonds de vallée.

Grâce à des comptages régulièrement faits tout au long de l'année et à la pesée des coupes successives, l'auteur a étudié l'utilisation des différents types de prairie et le rythme des rotations à prévoir.

\section{MISE A FEU DES PATURAGES}

Au Kenya, on a revisé au cours des dernières années la politique générale de contrôle des feux de brousse dans les zones d'agriculture européenne; le meilleur succès tient aux lignes pare-feu qui se multiplient grâce à des fonds gouvemementaux attribués seulement si les fermiers eux-mêmes s'en préoccupent et en particulier entretiennent les lignes. On utilise d'abord les pare-feux naturels : routes et rivières, dont les bords sont brûlés.

On a étudié à Madagascar le problème des feux de brousse du point de vue agrobiologique, sur des terrains différents. On a ainsi trouvé que l'incendie de prairie provoque une altération de l'activité biologique dü sol, caractérisée par la diminution de l'activité cellulolytique, localisée à la partie superficielle, et qui n'apparaît qu'au bout d'un certain temps; il semble que si la densité des bactéries cellulolytiques diminue, c'est moins dû à l'action du feu qu'à la disparition de la couverture du sol. D'ailleurs cette activité varie avec la puissance de la végétation herbacée et est pell marquée dans les prairies pauvres.

D'autre part, certains types de sols dont l'équilibre biologique est instable, sont plus sensibles que d'autres sols à l'action du feu. Quand il s'agit d'un feu de brousse (végétation mixte, herbacée et ligneuse) il y a également diminution plus ou moins grande de l'activité cellulolytique, mais il y a accroissement important de la densité des bactéries nitreuses.

La surexploitation, les feux de prairie qui dégradent le sol amènent de façon générale un accroissement de fertilité superficielle, avec multiplication explosivo dos bactérics nitrousas, on uno premièrc phase, suivie d'un effondrement de la fertilité.

A la station d'Thosy, à Nadagascar, des essais de mise à feu périodique sont poursuivis afin de déterminer les meilleures périodes à utiliser pour obtenir un bon pâturage et une production du sol satisfaisante. Une année d'expérience a permis d'arriver à la conclusion que, dans la province de Fianarantsoa :

les feux de contre-saison sont possibles pendant toute la saison des pluies,

qu'il est nécessaire de brûler les prairies à Danga et Vero quand les pluies sont bien établies,

que le feu le plus dangereux est celui qui est mis en août-septembre, 
que les touffes de ces deux dernières graminées restent vertes pendant la plus grande partie de la saison sèche,

que la prairie à Aristida doit être brûlée à des époques échelonnées si on veut obtenir un pâturage consommable en saison sèche,

que l'Aristida est très bien adaptée aux feux et peut sans inconvénient être soumise aux feux précoces, "à l'inverse du Danga et Trichopteryx qui ont besoin d'une humidité suffisante pour reverdir après l'incendie.

Au Swaziland un décret des autorités indigènes, venant en application de la recommandation de la Conférence des Sols de Léopoldville, interdit de labourer, pâturer et brûler à une distance inférieure à 20 mètres du bord d'un cours d'eau ou d'un bas fond humide. Il a été mis en application en 1954 sans difficulté. En certains endroits les bassins de réception de rivière ont été clôturés.

En A.E.F. on a pu constater que les grands incendies, tels qu'ils ont lieu dans les conditions naturelles, sont très nuisibles à l'amélioration du pâturage. Mais la mise à feu, lors des dernières pluies de la saison, dans la zone rıon pâturée où la végélation ne dépasse guère $30 \mathrm{~cm}$, permet une repousse de l'herbe pendant la saison sèche, repousse qui n'existe pas dans les zones non pâturées. Par contre la suppression des feux permet un développement de la végétation arbustive, qui peut faire craindre un envahissement des essences ligneuses après quelques années.

En Afrique du Sud, la conclusion de plusieurs centres spéciaux de recherches est que la mise à feu contrôlée est la seule façon pratique de contrôler l'envahissement des buissons sür de grands espaces. Cependant des éleveurs craignent que la disparition des buissons et des arbres, dont les feuillages sont intéressants en saison sèche, soit défavorable. Il est acquis en effet que, à cette période, l'herbe sèche a une teneur en protéine qui ne dépasse guère 2 à 3 p. 100. Mais l'expérience montre finalement que les troupeaux qui paissent sur des terrains débarrassés d'arbres et de buissons sauf quelquesi arbres d'ombrage, gagnent plus de poids que ceux qu'on maintient sur des pâturages envahis par la brousse. Les premiers pâturages voient l'herbe augmionter de 60 p. 100 parce qu'elle n'est plus gênée par les espèces ligneuses qui lui prenaient l'espace, la lumière, les éléments nutritifs et l'eau. L'eau surtout est abondamment prise par le système radiculaire très développé des arbres et évaporée par le système foliaire.

L'action des feux de brousse sur la microflore du sol peut se résumer ainsi : le nombre des microorganismes diminue notablement; les: champignons disparaissent pour un certain temps; les fixateurs d'azote aérobies sont détruits; leș organismes anaérobies qui ne sont jamais très actifs, semblent survivre. Les bacléries nitrifiartes sont luées ou réduites à un très petit nombre.

En Afrique du Sud, le nombre des zones de protection contre les feux de brousse a doublé au cours des dernières années; la création de comités de zone a permis de réduire considérablement le nombre des feux et l'extinction rapide de ceux-ci ; on en est arrivé à éviter les mises à feu dans des conditions qui auraient été néfastes pour le « veld ».' D'autre part, la feraison se' répand de plus en plus et réduit l'aire de propagation dés feux.

\section{III. - LES PRINCIPAUX GROUPEMENTS VÉGÉTAUX CONSIDÉRÉS COMIME PATURAGES}

Du point de vue de l'élevage, on distingue au Congo belge et au Ruanda-Urundi, les savanes guinéennes d'origine anthropique et qui ne se maintiennent qu'à la faveur des feux de brousse, et les savanes soudano-zambézéennes, dont la végétation est plus petite mais forme le plus souvent un gazon continu couvrant bien le sol.

Une classification condensée des types de végétation pour le Congo belge est la suivante: marais et prairies mouilleuses, savanes herbeuses, savanes boisées, bosquets xérophyles, forêts.

La nomenclature des milieux végétaux en Afrique noire (Trochain), est divisée en:
$1^{0}$ plantes herbacées exclusives ou dominantes tout au moins durant la saison favorable (prairie aquatique, prairie marécageuse, prairie altimontaine, pseudosteppe, savane steppique, savanes,)

$2^{\mathrm{e}}$ arbustes (moins de 10 mètres de hauteur) dominants (savane arbustive, savane hallier, savane garrigue, fruticées altimontaines, bush);

$3^{\circ}$ arbres (plus de $10 \mathrm{~m}$ de hauteur) dominants (savane arborée, savane-verger, palmeraie, bambousaie, savane forestière, forêt claire, forêt mélangée ombro-mésophile), forêt dense avec les sous-types : forêl dense ombrophile, forêt dense hémi-ombrophile. forêt parc, forêt dense hélophile, 
forêt dense littorale, forêt dense montagnarde, forêt dense de transition, Mangrove).

Dans « les amendements proposés » un nouveau schéma hiérarchique est présenté:

$1^{0}$ peuplement herbacé physionomiquement dominant (prairie, steppe et pseudo steppe, savane);

$2^{\circ}$ peuplement ligneux physionomiquement dominant et ouvert:

a) moins de $8 \mathrm{~m}$ de haut (savane arbustive et fruticées altimontaines),

b) plus de $8 \mathrm{~m}$ de haut (savane arborée, savane forestière);

$3^{\circ}$ peuplement ligneux physionomiquement dominant et fermé:

a) moins de $8 \mathrm{~m}$ de haut (bush),

b) plus de $8 \mathrm{~m}$ de haut (forêt claire, forêt sclérophylle, forêt dense, Mangrove, forêt parc, galerie forestière).

La classification des types de " veld 》 en Afrique du Sud (Acoks) comprend 7 types principaux:

$I^{0}$ les types forestiers tropicaux de la côte:

$2^{\circ}$ les types forestiers tropicaux de l'intérieur du pays :

$3^{\circ}$ les types de savane arbustive et buissonnante;

40 les types arides du Karoo;

$5^{\circ}$ les types buissonnants et forestiers de la zone de transition et de la zone tempérée;

6o les types purs de prairie;

$7^{\circ}$ les types de steppes à végétation buissonnante sclérophylle.

Jacques-Félix classe les herbages en Afrique intertropicale, selon le facteur prédominant en trois grands groupes: herbages anthropiques, climatiques et édaphiques:

A. - Les herbages anthropiques où l'influence humaine est déterminante mais non nécessairement intentionnelle sont subdivisés d'après le. climat en herbages subéquatoriaux post-forestiers et herbages tropicaux de sous-bois et de clairieres. Les herbages subéquatoriaux post-forestiers ne pourraient pas se développer ni se maintenir sous une haute pluviométrie essentiellement favorable aux climats forestiers dans les conditions naturelles. Primitivement les défrichements permettent l'envahissement des graminées, puis des feux annuels, très violents en raison du grand développement des herbes et maintiennent ces formations souvent exclusives de tout ligneux. Cependant sous une pluviométrie moindre (forêt sèche tropophile), le feu ne peut éliminer les essences forestières plus résistantes et l'on aboutit à des formations mixtes. La composition floristique de ces herbages est généralement homogène et réalisée essentiellement par des Panicées et des Andropogonées. Le clirnat est favorable à la production massive de fourrages de fauche. Il faudrait adopter une charge judicieuse du bétail. On pourrait ensuite essayer d'introduire des espèces stolonifères : Chloris gayana et Paspalum geminatum.

Les herbages tropicaux de sous-bois et de clairières se développent sous une pluviométrie moindre et constituent avec les arbres de forêt sèche, moins sensibles à des feux moins violents, dos formations mixtos caractéristiques dos zones guinéenne et soudanienne. Dans certains cas il y a non seulement influence mais bien intention humaine les deux zones climatiques considérées ayant été envahies à l'époque historique par des peuples pasteurs qui y ont trouvé les conditions favorables à l'élevage de leurs troupeaux et se sont plus spécialement fixés sur les plateaux du Fouta-Djallon en Cuinée française et de l'Adamaoua au Cameroun: La tâche du pasteur est souvent facilitée dans cette zone par l'existence de clairières naturelles, où les ligneux ne peuvent que difficilement pousser par suite de carapaces latéritiques, souvent très étendues. La composition floristique de ces herbages tropicaux est infiniment plus variée que celle des grandes savanes post-forestières. Outre les espèces déjà indiquées, on trouve de nombreuses espèces annuelles (Digitaria, Paspalum, Pennisetum, Hyparrhenia, Andropogon, Diectomis, Panicum, Brachiaria), qui ne repoussent pas après les feux, mais constituent souvent une ressource précoce. Le Melinis minutiflora couvre des pentes entières du M'Benna en Guinée Française, domine dans les jachères des moyennes pentes du pays Bamiléké au Caneroun, el constitue d'excellents pâturages. Le principe est, encore, d'atteindre ici à une densité $\mathrm{du}$ bétail en fonction de la production annuelle du fourrage, en convertissant les excédents fourragers de la saison des pluies en réserves pour la saison sèche.

B. - Les herbages climatiques comprennent ceux où l'influence du climat est suffisante ou du moins prépondérante, dans l'extension de formations herbeuses. On trouve les herbages steppiques de la zone sahélienne, qui s'étend du Sénégal jusqu'à la région nilotique (pluviométrie de 100 à $500 \mathrm{~mm}$ ). La strate herbacée est plus courte, souvent clairsemée, avec des arbres et buissons épineux (Acacia, Capparis, Zyziphus), plus rarement inermes (Bauhinia, Tamarindus). Le feu, trop peu intense, n'a plus d'action sur la strate ligneuse; c'est l'homme qui tend à les éliminer pour donner le feuillage à ses animaux. La composition floristique est encore fort variée, Panicées, Andropogonées, mais surtout 
les Choridées et des Aristidées. Les problèmes d'utilisation sont différents car ici le cultivateur sédentaire fait place à l'éleveur, qui tire tout le parti possible des herbages. L'art de la transhumance en exploite les plus modestes ressources. Dans le cas présent, ce n'est pas sur la flore herbacée que l'on peut agir efficacement mais sur les arbres: Faidherbia Albida est une essence particulièrement précieuse à cet égard (feuilles et gousses). Mais cc qui est important, c'est que ses feuilles se développent en saison sèche, alors que les pâturages sont secs et que ses gousses sont particulièrement épaisses, volumineuses, pouvant se conserver facilement et sont très appréciées des animaux. Enfin, -les feuilles tombant au contraire en saison des pluies. l'arbre ne gêne pas la croissance des cultures ni des herbages sous-jacents.

Des prairies pseudo-alpines à florule particulière (Bromus, Festuca, Poa, Trifolium, etc...) n'existent que dans les hautes montagnes (monts Bamboutos, Cameroun).

C. - Les herbages édaphiques: outre quelques herbages sur sables et latérites, il existe des herbages hydrophiles des bassins du Niger et du Tchad, qui s'étendant dans les zones de pâturages steppiques pauvres, jouent un rôle considérable dans l'élovage ct rallient les troupeaux transhumants en saison sèche. (Vetiveria nigrịtana dans les régions peu inondées, Echinochloa stagnina dans les régions où l'inondation est plus prolongée).
Au Kenya on distingue, par ordre d'humidité décroissante:

$1^{0}$ les prairies et forêts de montagne, avec de petites surfaces boisées et des prairies où domine Themeda triandra, et dans les endroits les plus humides, Pennisetum clandestinum qui, avec Trifolium johnstii, pout donner des pâturages productifs).

$2^{\circ}$ La savane arborée avec petits arbres dispersés (Combretum splendens, Erythrina tomentosa) et une association de graminées (Hyparrhenia, Cymbopogon).

$3^{\circ} \mathrm{La}$ région côtière à herbes hautes et buissons dominés par des baobabs; il y a de grandes clairières à Hyparrhenia rufa.

$4^{\circ}$ La région de savanes arbustives et prairies ouvertes qui comprend des acacias (A. drepanolobium) dispersés dans des pâturages où domine Themeda triandra.

$5^{\circ}$ La pseudo-steppe qui couvre les deux tiers du Kenya: association de buissons où dominent des Acacia, Commiphora, l'herbe la plus répandue étant Chryzopogon aucheri var. quinqueplumis.

$6^{\circ}$ La brousse désertique qui vient comme importance après l'association précédente; buissons bas avec quelques arbres rabougris, formant une faible couverture, le sol nu étant toujours visible. Les buissons qui dominent sont encore: Commiphora, Acacia, les Graminées des Aristida. Cette association peut ētre considérée comme dérivée de la précédente dans des conditions plus sèches.

\section{IV. - LES PATURAges DES PRINCIPALES RÉgIONS}

\section{PRESQU'ILE DU CAP VERT}

Les graminées fourragères de Ila presqu'île du Cap Vert, région qui représente d'autres zones d'Afrique tropicale, sont les suivantes:

Acroceras zizanioides, Andropogon amplectens, A. gayanus, A. gayanus var. geminus, A. gayanus var. squamulatus, $A$. pinguipes, Aristida adscensionis, $A$. hordeacea, $A$. longiflora, $A$ i stipoïdes.

Beckeropsis uniseta, Bothriochloa glabra, Brachiaria deflexa, $B$. distichophylla, B. hagerupii, B. mutica, B. ramosa, B. xantholeuca.

Cenchrus biflorus, C. ciliaris, Chloris pilosa, Ch. prieuril, Coix lacryma jobi, Commelinidium nervosum, Ctenium elegans, Cymbopogon citratus, C. giganteas, Cynodon dactylon.

Dactyloctenium aegyptiacum, Dichantium annulatum, D. papillosum, Digitaria chevalieri, D. gayana,
D. longiflora, D. perrotetii, D. sanguinalis, Dinebra retroflexa, Diplachne fusca.

Echinochloa colona, E. crus galli, E. pyramidalis, Eleusina indica, Eragrostis cambessediana, E. cilianensis, E. cillaris, E. linearis, E. squamata, E. tenella, E. tremula, Eriochloa nubica.

Hackelochloa granularis (= Manisuris granularis); Hemarthia fasciculatea, Hyparrhenia dissoluta.

Imperata cylindrica.

Latipes senegalensis, Leersia hexandra.

Olyra latifolia, Oplismenus burmanii, Orysa barthii.

Panicum laetum, P. longijubatum, P. maximum, P. repcns, Paratheria prostata, Paspalidium geminatum, Paspalum scrobiculatum, $P$. vaginatum, Pennisetum longistylum, $P$. mollissimum, $P$. pedicellatum, $P$. polystachyon, $P$. rogeri, $P$. pycnostachyum, $P$. typhoides, $P$. aff. violaceum, Perotis indica, Phragmites communis, Pobeguinea correcta, Rottboellia exaltata. 
Saccharum officinarum, Schizachyrium brevifolium, Sc. exile, Sc. pulchellum, Schoenefeldia gracilis, Setaria barbata, S. chevalieri, megaphylla, S. pallidifusca, S. verticillata, Sorghum drummondii, S. vulgare, Sporobolus festivus, $S$, granularis, $S$. minutiflorus, $S$. robustus, $S$. spicatus, $S$. virginicus.

Stenotaphrum secundatum.

Urochloa lata.

Vitiveria nigritana.

\section{GRAMINÉES, TYPHACÉES ETT CYPÉRACÉES DE LA RÉGION SAHÉLO-SOUDANAISE DU SOUDAN (A. Mallamaire).}

Graminées. - Vetiveria nigritana', Andropogon gayanus, A. tectorum, Eragrostis gangetica, E.cilianensis, $E$. linearis, $T$. tremula. Digitaria velutina, $D$. adscendens, D. acuminatissima, D. gayana, $D$. lecardii, D. leptorachis, $D$. debilis, Panicum turgidum, $P$. laetum, $P$. repens, $P$. longijubatum, Paspalum scrobiculatum var. commersonii, Echinochloa pyramidalis, E. stagnina, E. colona, Rottboellia exaltata, Cymbopogon schoenanthus, C. proximus, C. giganteus, Hyparrhenia dissoluta, Heteroposon contortus, Brachiaria fulva, $B$. deflexa, Urochloa trichopus, Setaria sphacelata, S. verticillata, Pennisetum setaceum, Cenchrus biflorus, C. ciliaris, Aristida acutiflora, $A$. adscensionis, A. pallida, A. pungens, Tragus racemosus, Latipes senegalensis, Spor obolus glaucifolius, S, pyramidalis, Schoenefeldia gracilis, Cynodon dactylon, Chloris pilosa', Eleusina indica, Dactyloctenium aegyptiacum, Saccolopis interrupta, Oryza perensis, 0 . barthii:

Typhacées. - Typha australis.

Cyperacées. - Cyperus articulatus, $C$. esculentus, C, maculatus, Fimbristylis exilis.

\section{RÉGION PLUVIEUSE DU SOUDAN (ÉGYPTIEN)}

Les. pâturages comprennent des graminées annuelles dressées, une des plús importantes étant Sorghum purpureus sericeum, avec Rotboellia exàltata, Sorghum spp; Cymbopogon nervatum, Brachiaria obtusiflora, et dans les pâturages plus boisés, Beckeropsis nubica. Là où l'argile grise humide domine, généralement Brachiaria obtusiflora est à l'état presque pur, quelquefois mélangé à Eriochloa nubica.

$\therefore$ Certaines espèces de légumineuses herbacées ou légèrement ligneuses existent à l'état naturel et pourraient entrer dans la constitution d'herbages graminées-légumineuses. Parmi elles, Clitoria terneata, Glycine borianii, et Indigofera subulata, L'association Chloris gayana, Clitoria terneata donne de bons espoirs.

\section{NORD-CAMEROUN}

On rencontre les' graminées suivantes:

Acroceras amplectens, que les animaux mangent en vert ou en grains.

Andropogon gayanus, A. gayanus var, genuinus, $A$. tectorum, A. pseudapricus, A. schirensis, A. sp., herbes que les animaux, surtout les chevaux, ne mangent que jeunes.

Aristida adscensionis, mangé exceptionnellement; $A$. hordeacea, consommé en vert par tous, les herbivores; $A$. kerstingii, A. Iongiflora, peu recherchés.

Beckeropsis uniseta, mangé en herbe.

Brachiaria distichophylla, au bord des cours d'eau; B. brachylopha, B. regularis, B. falva, mangé.

$B$. kotschyana, délaissé; $B$. lata, mangé; $B$. mutica, assez recherché.

Cenchrus biflorus.

Chloris pilosa (terrains sablonneux du bord de l'eau) mangé en herbe et en grains, Ch. prieuri, bon fourrage, Ch. pycnothrix, également; $C h$. robusta et C. lamproparia, en herbe seulement.

Ctenium canescens, mangé seulement pari les bovins; et $C$. newtonii, délaissé par les chevaux.

Cymbopogon citratus et C. giganteus, non consommés.

Cynodon dactylon.

Dactyloctenium aegyptium.

Digitaria gayana, $D$. lecardii, $D$. adscendens, $D$. squamata, $D$. longiflora, $D$. velutinai, tous mangés en herbe et en graines; la plus appréciée est $D$. adscendens, var. criniformis.

Dinebra retroflexa, recherchée.

Echinochloa colona, E. pyramidalis, E. stagnina, E. colina, mangés.

\section{E. obtusiflora,}

Eleusina corocana; El. indica.

Eliomurus elegans, délaissé par̆ les chevaux.

Elytrophonus spicatus, délaissé.

Eragrostis aspera, mangé jeune; E. cambessediana, délaissé par. les chevaux, E. cilianensis, mangé; F. ciliaris, mangé; $E$. namaguensis, rarement mangé ; E. pilosa, mangé ; E. squamata, recherché.

E. tremula, E: turgida.

Eriochloa acrotricha, E. linearis, E. gangetica, tous mangés.

Hackelochloa granularis; mangé:

Heteropogon contortus, généralement délaissé par les chevaux.

Hyparrhenia diplandra, mangé par les bovins seulement; $H$ : rufa, mangé en herbe seulement; $H$. subplumosa, également; $H$. dissoluta, $H$. hirta; 
chrysargyrea, H. soluta, mangé jeunes, Imperata cylindrica.

Ischaemum brachyatherum, mangé jeune.

jardinea congensis, amer peu consommé.

Leersia hexandra, pas consommé.

Leptocloa coerulescens, mangé.

Loudetia phragmitoides, pas consommé; L. simplex, mangé en herbe seulement; $L$. togoensis, peu apprécié.

Melinis minutiflora.

Oryza barthii, mangé en herbe seulement; $O$. sativa.

Oxythenanthera abyssinica, mangé.

Paniceum anabaptistum, peu consommé; $P$. humile, mangé en herbe; $P$. longijubatum, également $P$. repens, mangé; divers Panicum, en général mangés jeunes, dont: laetum, $P$. drageanum, $P$. aphanoneuron.

Paspalum scrobiculatum; P. sp., mangés en herbe. Perotis indica, mangé en herbe.

Pennisetum purpureum, $P$, setaceum, bons et pouvant convenir pour l'ensilage; $P$. pedicellatum, très bon; $P$. polystachyum, $P$. ramosum, $P$. subangustum, tous bons.

Perotis indica, mangé.

Phragmites communis.

Rhynchelytrum repens, mangé jeune.

Rottboellia exaltata, bon.

Sacciolepis interrupta, très bon; S, micrococca, bon.

Saccharum spontaneum, S. spontaneum var. aegyptiacum, mangés jeunes; $S$, officinarum.

Schizachyrium exile, non mange; $S$. semiberbe, mangé jeune.

Setaria barbata, S. pallidifusca, S. sphacelata, $S$. verticillati. $S$. anceps, tous mangés.

Sorghum arundinaceum, délaissé; $S$. aterimum, mangé; $S$. caudatum, $S$. vulgarc, $S$. vogelianum.

Sporobolus aequiglumis, $S p$. festivus, Sp. pyramidales, mangés.

Tehapogon spathaceus, mangé.

Thelepogon elegans, mangé.

Urochloa lata, $U$. trichopus, bons.

Vetiveria nigritana, mangé jeune.

Vassia cupidata, bon.

\section{GRAMINÉES ET LÉGUMUNEUSES DES LLANOS DU VENEZUELA}

Les « llanos 》; steppes caractéristiques du Venezuela, nourrissent la plus grande partie des bovins. Ceux-ci y trouvent:

Graminées. - Leersia hexandra, Cynodon dacty- lon, Sporobolus indicus, $S$. virginicus, Paspalum plicatulum, $P$. fasciculatum, $P$. coryphaeum, $P$. notatum, $P$. conjugatum, $P$. repens, $P$. fimbriatum, $P$. virgatum, Eragrostis maypurensis, Axonopus compressus, Panicum laxum, $P$. fasciculatum, Andropogon bicornis, A. selbanus, Trachypogon plasmosus, T. montufari, Antiphora hermaphrodita, Eleusine indica, Chloris mollis, Ch. polydactyla, Luziola pittieri, -Digitaria horizontalis, Eriochloa punctata, Pennisetum setosum, Imperata cylindrica, Heteropogon contortus, Holcus lanatus, Melinis minutiflora, Panicum maximum.

Légumineuses. - Desmodium purpureum, $D$. canum, D. molle; Vigna vexillata, V. luteola, Teramnus sp.; Centrosoma sp.; Calopogonium spp.

\section{RÉGION MONTAGNEUSE DE L'OUGANDA}

Les graminées des régions montagneuses de l'Ouganda sont les suivantes (non comprises les espèces des zones plus basses qui poussent aussi en altitude):

Acritochaete volkensii, Agrostis bryophylla, A. gracilifolia, A. kilimandscharica, A. lactinartha, A. leptophylla, $A$. midbraedii, $A$. schimperiana, $A$. soraria, A. taylord, Aira caryophyllea; Andropogon abyssinica, $A$. amethystinus, $A$. pilosellus, $A$. polyatherus; Anthoxanthum nivale; Arundinaria alpina.

Bromus cognatus, B. leptocladus, N. runosoroensis.

Calamagrostis epigeios.

Deschampsia angusta, D. caespitosa, D. caespitosa var. oliveri, $D$. flexuosa var, afromontana.

Ehrherta abyssinica, E. ereita; Eragrostis paniciformus, E. volkensii; Exotheca abyssinica.

Festuca abyssinica, $F$. gelida, $F$. gigantea, $F$. ridigale, F. schimperiana.

Helictrotrichon elorgatum, $H$. lachnanthum, $H$. milanjianum; E. volkensil; Exotheca abyssinica.

Festuca abyssinica, F. gelida, F. gigantca, $F$. ridigala, $F$. schimperiana.

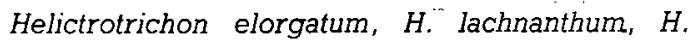
milanjianum; Hyparrhenia finitima, $H$. 'hirta, $H$. pilgeriana.

Koeleria cristala.

Lasiurus maitlandii; Leptospis cochleata.

Panicum adenophorum, $P$. stuhlmannii; Pennisetum glabrum, P. mildbroedis, P. trachyphyllum; Pentachistis borussica, imatungensis, $P$. minor, P. rawenzoriensis; Poa glacialis, P. leptoclada, P. schimperiana; Pseudobromus silvaticus.

Setaria acromuleana; Snowdenia microcarpha, S. scabra; Sporobolus capcnsis, S. filipes, S. helvolus, S. patulus, $S$. pellacidus, $S$. treptogynogerontoquea.

Tricholaena teneriffa; Tripogon snowdenü. 


\section{V. - UTILISATION DES PATURAges NATURELS}

\section{INFLUENCE DU PACAGE DU BROUTAGE ET DU FAUCHAGE}

L'influence de la fréquence de la coupe sur différentes espèces fourragères a été étudiée au Salvador. Chaque espèce était coupée à un, deux et trois mois d'intervalle et pour chaque coupe on pratiquait trois hauteurs différentes, neuf traitements étant ainsi effectués. On opérait sur légumineuses (Dolichos lablab, Cajanus cajan, Desmodium nicaraguense) et graminées (Pennisetum purpureum, Panicum maximum, Hyparrhenia rufa, Melinis minutiflora, Chloris gayana).

Les légumineuses ne résistèrent pas au traitement. Quant aux graminées, le plus fort rendement en matière sèche fut obtenu avec les coupes à trois mois d'intervalle, la hauteur de coupe variant avec la stature de l'espèce. Les coupes à un mois donnent des récoltes plus riches en protéine que les coupes à deux ou trois mois.

Les analyses faites dans l'Inde sur des coupes différentes de Napier grass et Guinea grass montrent que les coupes faites tous les mois ou tous les deux mois sont de meilleure qualité que celles qui sont faites tous les trois mois. Plus les intervalles sont longs plus la teneur en cellulose est grande: pour les deux $\epsilon$ spèces, le pourcentage est respectivement de 31,35 et 35,26 après un mois; 34,02 et 38,64 après deux mois; 35,99 et 39,84 après trois mois.

Inversement, la teneur en protéine diminue quand augmentent les intervalles; pour le Napier elle est de $8,98,4,97$ et 6,92 p. 100 pour un, deux ou trois mois; pour le Guinée $11,05,4,45$ et 3,24 p. 100. Le premier ne doit pas être coupé après un ou deux mois ou les tiges et les feuilles deviennent dures. Le second demeure plus longtemps tendre.

Dans l'Inde, on a soumis à l'analyse des échantillons d'Andropogon sorghum, variété kaki, depuis la deuxième semaine de pousse jusqu'à maturité. On a observé que:

$1^{0}$ la matière organique augmente progressivement jusqu'à la fin;

$2^{\circ}$ les protéines brutes diminuent dans la plante enlière à la $9^{\mathrm{e}}$ semaine, puis à la $11^{\mathrm{e}}$ et à la $17^{\mathrm{e}}$. Par rapport à la $3^{\mathrm{e}}$ semaine, il y a une baisse totale de 65 p. 100. Dans les tiges, la diminution est continuelle et dépasse 77 p. 100, l'azote libre augmente par bonds successifs et atteint finalement une augmentation de 45 p. 100 ;

$3^{\circ}$ l'extrait éthéré diminue progressivement, la baisse atteignant 70 p. 100; 4o la cellulose augmente à parti de la ge semaine surtout dans les tiges où le taux est doublé dès la 11 e semaine;

$5^{\circ}$ les cendres diminuent à partir de la $5^{\mathrm{e}}$ semaine, jusqu'à 40 p. 100. Le calcium baisse au début, augmente de la $5^{\mathrm{e}}$ à la 11 e semaine où il baisse brusquement, puis palier.

Le phosphore baisse de la $3^{\mathrm{e}}$ à la $5^{\mathrm{e}}$ semaine, à nouveau de la $7^{\mathrm{e}}$ à la $9 \mathrm{e}$, puis encore jusqu'à la $11 \mathrm{e}$. La baisse totale est de 69 p. 100.

D'autres analyses portant sur la variété blanche d'Andropogon sorghum, donnent les résultats suivants :

$1^{0}$ la matière organique augmente progressivement;

$2^{\circ}$ les protéines brutes diminuent presque de moitié dans la plante entière entre la $3^{e}$ et la 9e semaine; la dimïnution est moins accentuée dans les feuilles que dans les tiges;

$3^{\circ}$ l'extrait éthéré diminue par rapport au taux initial de 57 p. 100 dans la plante entière;

$4^{\circ}$ la cellulose brute croît progressivement jusqu'à la 9 e semaine; à ce moment, elle augmente brutalement, l'augmentation finale étant de 57 p. 100 (dans les feuilles, 40 p. 100 seulement);

$5^{0}$ la diminution des cendres commence à la $5^{\text {e }}$ semaine et atteint 45 p. 100 . Le calcium baisse jusqu'à la $9^{\mathrm{e}}$ semaine puis se maintient à peu près, la baisse atteignant 66 p. 100 . Le phosphore décline aussi progressivement jusqu'à 62 p. 100.

On a recherché aussi dans l'Inde, l'influence des coupes mensuelles sur diverses plantes : Decanthium annulatum, Amphilophis adorata et glabra, Iseilema laxa, Themeda trimula, Pennisetum orientale, Panicum repens, Chrysopogon montanus,: Schima nenosum et Heteropogon contortus.

Ces coupes mensuelles, chez toutes les plantes, permettent de maintenir un taux élevé en protéines, $\mathrm{Ca}$ ct P. Par contre les variations de la cellulose et de l'extractif non azoté sont opposées à celles des protéines; mais l'acide phosphorique varie parallèlement aux protéines, le Ca inversement.

\section{LES DIVERS MODES D'EXPLOTTATION DES PATURAGES NATURELS}

Le " veld " naturel de la Rhodésie du Sud couvre 99 p. 100 de cette région; c'est sa plus grande richesse et sa préservation est d'une importance 
capitale. Les études menées jusqu'à maintenant ont conduit à deux points essentiels:

$1^{\circ}$ une charge de bétail bien inférieure à la capacité maximum du veld. En règle générale, pour les velds ayant beaucoup de plantes vivaces, le pacage est suffisant quand subsistent encore 30 à 40 p. 100 de l'herbe non broutée en fin de période de pâturage.

$2^{\circ}$ période d'arrêt du pâturage en saison humide, quand les plantes poussent, pour permettre aux espèces vivaces de constituer leurs réserves et aux espèces annuelles de former leurs graines.

Le fauchage permet de combattre l'envahissement des buissons; il faut l'accompagner de travaux de nettoyage à la main; il faut faúcher entièrement le pâturage, sinon la zone fauchée serait surpâturée ensuite par le bétail.

Pour un veld buissonneux pouvant être pâturé toute l'année, on multiplie le système suivant: rotation des pâturages selon plusieurs systèmes; système à 4 pâtures et 3 troupeaux; système à 4 pâtures et 2 troupeaux; système le plus intensif à 4 pâtures avec fauche et un troupeau, tout cela lié évidemment à la création de clôtures et de points d'eau.

En Ouganda on a adopté, pour les pâturages créés un système de 6 paddocks de même surface (au moins 40 ares 46 pour chacun). Les animaux restent 10 jours dans chaque paddock, la rotation se fait en deux mois. Si on fait varier le nombre des animaux par paddock, on peut faire consommer toute l'herbe dans la période de 10 jours. A la fin de cette période, on fauche les refus.

Au Basutoland, en 1954, la question du contrôle a été étudiée par le Conseil qui a décidé:

10 que, sous la direction du "Chef principal ", les chefs de district doivent contrôler le pâturage des montagnes de leur zone et les points de rassemblement du bétail établis avec leur agrément;

$2^{\circ}$ la capacité de charge du bétail doit être établie et utilisée pour l'attribution des zones de rassemblement du bétail;

$3^{0}$ les terres cultivées sur pentes escarpées doivent être reconverties en herbages:

$4^{\circ}$ une rotation contrôlée des pâturages de montagne sera déterminée par la loi.

\section{REALISATIONS DANS DIVERSES RÉGIONS CEAUDES}

En diverses stations de l'Inde, on a essayé des associations de graminées et de légumineuses. Au point de vue du rendement en fourrage, c'est l'association Pennisetum pedicillatum-Melilotus alba qui réussit le mieux, ou encore Cenchrus ciliarisluzerne. Si on recherche la restauration de la fertilité du sol, c'est de préférence à Cynodon dactylonMedicago denticulata qu'il faut recourir; cette association améliore la structure du sol, augmente le taux d'azote. Elle permet un contrôle de l'érosion même sur des pentes de 1 à $2 \mathrm{p}$. 100 . On peut améliorer le mélange par adjonction de Medicago lupulina pour augmenter et prolonger la durée de production de légumineuses.

Pour une couverture végétale plus forte, on peut adjoindre à l'association Pennisetum-Melilotus des bandes alternées de Pennisetum-Phaseolus mungo et en semant le molilot après la récolte de Phaseolus, en appliquant du phosphate.

Dans lc Nilgris (Inde) les meilleures espèces pour le maintien du sol sont: Pennisetum clandestinum, Tripogon bromoides, Eragrostis anabilis et Cynodon dactylon. Themeda triandra, Ischaemum ciliare et Paspalum dilatatum sont aussi de bons stabilisateurs.

Au Kenya, les essais d'introduction d'espèces exotiques ont porté sur 300 variétés de graminées et de légumineuses, avec une collection de 72 variétés de luzerne; les espèces qui ont donné les plus grands espoirs sont: Rhodes Grass, Setaria sphacelata, trèfle blanc du Kenya (700 kg à l'ha), et Trifolium ruspellianum qui a donné $290 \mathrm{~kg}$ de semences à l'ha.

En Rhodésie du Sud, les essais réalisés au cours des récentes années ont montré que les meilleures espèces pour la création de pâturages sont des vanétés de Chloris gayana, de Panicum coloratum var. makarikariensis, de Cenchrus ciliaris et de Setaria sphacelata. On associe parfois à ces graminées des légumineuses: Lespedeza stipulacea; Trifolium masaiense, Desmodium tortnosim (purpureum).

Au Soudan, on a préconisé les herbes suivantes: Bothriochloa retusa, Pennisetum purpureum, Chloris gayana, seules ou associées à des espèces retombantes comme Brachiaria decumbens ou Urochloa mosambicensis.

L'expérience de cinquante années en Afrique orientale montre que pour la création de prairies de graminees, ce sont les espèces indigènes qui donnent les meilleurs résultats, les comparaisons portant sur la palatabilité, la facilité d'éradication quand cela devient nécessaire, les facultés de semis naturel et l'aptitude à la persistance même lorsque la prairie est souvent scumise à une exploitation intensive. 
En tenant compte de la quantité de graines qui peuvent germer à l'hectare, et non de la quantité semée, on a déterminé au Kenya la proportion de kilogramme/hectare de graines des espèces intéressantes. Pour Chloris gayana, la densité minimum est de $1,700 \mathrm{~kg} / \mathrm{ha}$; on peut monter jusqu'au double. Pour Melinis minutiflora 1,1 kg/ha. Pour Panicum maximum $0,550 \mathrm{~kg} / \mathrm{ha}$. Si on sème en lignes les quantités peuvent être diminuées.

\section{FUMUURE}

Sur les pâturages des régions élevées du Kenya, les essais d'engrais ont montré que le sulfate d'ammoniaque augmente la production et la teneur en protéine de certains pâturages naturels et des pâturages artificiels dont il facilite l'établissement. On peut l'appliquor à plusieurs reprises pendant la période de croissance, mais cette méthode ne peut se justifier que pour des pâturages clôturés, si le troupeau est suffisant, s'il y a des points d'eau ou encore si on conserve le fourrage.

Les engrais phosphatés accroissent également la productivité et la qualité des fourrages, il faut y ajouter des apports périodiques d'azote. Au semis d'une prairie temporaire, les bumes proportions d'engrais azoté sont de $180 \mathrm{~kg} / \mathrm{ha} ;$ l'établissement de la prairie demande l'apport de phosphates solubles, la quantité ne dépassant pas $350 \mathrm{~kg} / \mathrm{ha}$ de superphosphate simple. Ces premières applications n'influent pas sur la productivité au-delà de la première coupe, mais le phosphate peut continuer à augmenter la valeur nutritive du pâturage.

Les engrais azotés et phosphatés et, à un degré mal connu, la potasse et la chaux, ont une influence sur la composition floristique d'une prairie, mais aussi sur les animaux qui la pâturent. Pour utiliser au maximum l'amélioration fournie par les engrais, il faut soigneusement contrôlcr lo pâturage pour maintenir un équilibre favorable des espèces.

En Afrique du Sud, l'expérience a montré que, avec des applications de sulfate d'ammoniaque, allant de 180 à $360 \mathrm{~kg}$ par ha, on fait passer la production d'Eragrostis curvula qui, était de 2 tonnes, à 6 et $7,5 \mathrm{t}$. En même temps, la teneur du foin en protéine passe de 8,4 p. 100 à 14,15 et 18 p. 100 .

On a aussi déterminé la valeur respéctive de différents engrais à l'égard du rendement de Chloris Gayana ou du mélange de cette dernière avec la luzerne. Dans l'Est Africain, on a déterminê l'influence de l'azote ammoniacal et nitrique sur lés prairies temporaires de Melinis minutiflora.

On a aussi au Kenya, déterminé les avantages des engrais dans les prairies de montagne.
Mais c'est surtout en Afrique du Sud que l'étude des engrais sur les pâturages de diverses zones a été le plus poussé.

\section{DESTRUCTION DES MAUVAISES PLANTES RESTAURATION DES PATURAGES}

Dans l'Est africain, on a expérimenté largement en ce qui concerne la destruction des arbres pour le contrôle des glossines ou l'amélioration des pâturages; cela sur des types de végétation différente. Dans la savane dense à Commiphora-Combretum qui nous intéresse, on a utilisé par avion, sur des bandes de $45 \mathrm{~m}$ de long et $400 \mathrm{~m}$ de large des solutions de' $2,4,5 \mathrm{~T}$ butyl ester dans l'huile diesel, à une concentration calculée pour que le dépot moyen soit de $0,560 \mathrm{~kg} / \mathrm{ha}$. Les espaces d'Acacia, Albizzia, Commiphora, Grewia sont rapidement défeuillées, les Lanna, quelques Combretum plus lentement; d'autres Combretum sont, peu touchés. Mais la repousse survient d'autant plus vite que l'effeuillage a été plus rapide.

Si on opère, non plus par avion mais avec des appareils à dos, le 2,4,5 T à 80 p. 100 appliqué sur Tarchonanthus camphoratus, la repousse se fait après deux mois ; par contre on peut détruire Commiphora Shimperi, C. subsessilifolia, Euphorbia matabelensis à des doses allant de 0,67 à 22,1 ' ha à la fn de la saison sèche avec ou sans entailles et sur troncs fraichement coupés; mais pour que le traitement soit économique, il faudrait que les doșes soient moindres; on a pu réaliser cela sur. C. shimperi.

Sur Isoberlinia globiflora, on a obtenu de bons résultats en écrasant 20 à $30 \mathrm{gr}$ de sulfate d'ammonium sur la souche. Sur Dichrostachys glomerata, le traitement par 2,4,5 T sur les souches fraîchement coupées a donné de bons résultats. Sur Solanum incanum, mauvaises herbes pérennes fréquentes dans les pâturages, divers herbicides donnent des résultats irréguliers, les meilleurs étant avec le butyl 2-4-D.

Dans le Tanganyika central, steppe boisée et arbrisseaux sarmenteux à feuilles caduques, les cultures sont hasardeuses; on essaie de transformer cette steppe en pâturage, en ménageant la transition par une période de culture semi-intensive.

A un premier stade, l'amélioration de la méthode traditionnelle de défrichement à la pioche, a permis l'élimination de rejets, l'introduction du « ley farming 》 et l'utilisation de faucheuses.

Les bulldozers, les déracineurs et les hormones pour destruction des arbustes reviennent à 65.000 
francs par hectare. On laisse sur pied les arbres qui donnent de l'ombrage ou de la provende: Acacia spirocarpa, A. albida. On introduit Pithecolobium saman.

Pour lutter contre l'envahissement du pâturage de brousse par les buissons on utilise en Rhodésie du Sud :

$1^{\circ}$ les produits chimiques : arsenic, huiles spéciales, certaines donnant de bons résultats, d'autres ne contrôlant pas certaines espèces;

$2^{\circ}$ des troupeaux de chèvres;

$3^{\circ}$ le fauchage qui demande un nelloyage préalable des buissons, opérations difficiles en raison du prix de revient;

$4^{0}$ destruction par le feu qui donne de bons résultats à condition de l'exécuter aussi tard que possible en fin de saison sèche, de le faire violent, de ne pas faire paître avant rétablissement du pâturage, de mettre à feu à intervalles réguliers.

En Amérique, on a créé tout un matériel de débroussement mécanique: bulldozers, matériel pour le ramassage et la mise en tas de broussailles, rateaux débroussailleurs, bulldozers d'abatage, arrache-souches, coupe-racines, extirpateurs spéciaux, etc.

Le " coupe-buisson rotatif » permet de nettoyer 0,8 ha à l'heure de broussailles de densité moyenne; on laisse sur le sol le matériel coupé comme couverture, ce qui constitue un lit pour semer les graminées. Pour éviter que les mauvaises herbes ne remplacent les buissons, il faut empêcher de paître pendant les deux saisons de pousse de l'herbe qui suivent l'emploi de la machine. Certaines espèces buissonneuses qui rejettent sous terre ne sont pas détruites. Dans certaines régions des U.S.A. ce procédé augmente la production de fourrage de 20 à 80 p. 100 la première année, de 100 à 200 p. 100 au bout de deux ans, et même plus.

L'incendie étant la méthode de défrichement la moins onéreuse pour aménager les terrains de pacage, envahis par la végétation ligneuse, une technique de mise à feu des terres embroussaillées a été mise au point par la station forestière d'essais de Californie.

Cette technique consiste à obtenir un maximum de destruction en une seule fois, le jour le plus propice, en créant un "fire storm " (feu très violent). En allumant des feux dispersés sur une surface à débarrasser de sa végétation ligneuse, on arrive à provoquer un incendie intense qui crée un appel d'air, amenant le degré d'ignition à un point suffisamment élevé pour détruire tout buisson et arbuste.
La surface à aménager est limitée par un pare-feux et un certain pourcentage de buissons sont déracinés et rassemblés au bulldozer. Dans bien des cas, les procédés mécaniques de destruction des mauvaises herbes, outre qu'ils sont très onéreux, ne peuvent être utilisés en raison des conditions de terrain.

Le "T.C.A. " ne réussit pas contre l'Imperata mais est efficace contre les Cyperacées et Ageratum conyzoïdes; cependant certaines Cyperacées sont plus ou moins résistantes: Pycreus tremulus, Scleria baroni, Courtoisia cyperoides.

Avec un produit arsenical (Weedicida) à 2 p. 100 de mouillant on détruit: Les Lantana, Leucaena glauca, Acacia farnesiana, Mimosa invisa, dont les souches sont mortes après plusieurs applications.

La transformation d'une savane à Pennisetum du Congo belge, qui ne comporte que de rares arbustes, est moins onéreuse quand on a recours à la coupe mécanique avec des "brush cutters 》 tirés par un Caterpillar (500 fr belges par ha) que si on pratique la coupe manuelle (600 fr belges).

\section{Lutte contre l'Imperata au Queensland.}

Au Queensland, où Imperata cylindrica, var. major est très répandue, on considère qu'une utilisation correcte des pâturages suffit souvent à empêcher l'envahissement: rotation, hersage pour disperser les excréments du bétail et augmenter ainsi la fertilité du sol. Quand la prairie est envahie, il existe plusieurs modes d'extermination. Le labourage dans les zones cultivées est un bon moyen; on peut aussi alterner les cultures et le pâturage dans les exploitations mixtes. Le labourage de petites parcelles à la saison humide et le réensemencement en Paspalum ou Melinis minutillora est aussi efficace. Le fauchage présente l'avantage de ne pas exposer le sol à l'érosion; on diminue rapidement la proportion d'Imperata en fauchant trois fois par an.

Les graines plumeuses de l'Imperata sont dispersées loin par le vent; mais elles ne peuvent franchir une épaisseur de forêt de $30 \mathrm{~m}$ de large; pour qu'elles atteignent une clairière, il leur faut une brèche assez large (route, chemin de fer).

Certains auteurs estiment que la suppression des feux de brousse amènerait au bout de dix ans la disparition de l'Imperata. Mais au contraire, on a recours au feu pour la destruction. Si on brûle, il faut aussitôt semer une plante de couverture à croissance rapide pour ombrager le sol aussitôt que possible. Le procédé le plus efficace est le bêchage à $20 \mathrm{~cm}$ au moins, suivi d'arrachage et ramassage puis brûlage des tiges souterraines. 
Cela demande beaucoup de travail. On peut aussi labourer, puis ramener les rhizomes en surface par plusieurs passages au pulvérisateur. Si le labour est impossible, fauchages fréquents, qui épuisent les réserves des rhizomes.

L'inondation est aussi un moyen.

On a recours aussi aux methodes chimiques. L'arsenite de sodium pulvérisé (17 kg pour 700 litres d'eau par hectare, ou même 7 à $10 \mathrm{~kg}$ si on ajoute un mouillant) amène la disparition si on répète tous les dix jours, sans faucher ou brûler auparavant. Le trichloro-acétate de sodium donne aussi de bons résultats (solution à $10 \mathrm{p}$. 100). On a recours aussi à des pulvérisations d'huiles spéciales.

Les méthodes culturales sont aussi employées. Le paillage étouffe l'Imperata. Aussitôt après sa destruction, il faut établir une plante de couverture ou engrais vert. Comme plantes de couverture, selon les lieux, on peut recourir à Tephrosia candida, Centrosema pubescens, Dolichas hosii, Mimosa invisa, Crotelaria juncea, Vigna hosei, Indigofera endecaphylla, Calopogonium mucunoides, Desmodium polycarpum, Canavalia rosea. Comme engrais verts, entre les rangées d'arbres s'il s'agit de plantations: Tephrosia candida, Mucuna utilis, Pueraria thumbergiana, Passiflora foetida, Phaseolus lunatus, Cajanus indicus.

En Malaisie, des essais de destruction d'Imperata cylindrica avec divers herbicides, employés seuls ou mélangés à diverses huiles, l'application se faisant avec ou sans houage précédant les pulvérisations n'ont pas donné des résultats parfaits, la repousse se produisant presque toujours après 6 mois.

La jachère à Imperata cylindrica maintenue non brûlée pendant 6 ans permet une bonne culture ultérieure de coton, mais le débroussement est difficile; en plantant du manioc en fin de rotation, l'ombrage empêche la réinstallation de l'Imperata.

Au Queensland, où la surcharge des pâturages ajoutée à la sécheresse avait récemment fait disparaftre par place la couverture en graminées, les sillons tracés sur les pâturages selon les courbes de niveau se sont révélés un des moyens les plus, efficaces.

\section{VI. - GRAMINÉES}

\section{ANDROPOGONAE}

\section{Genre Amphilophis}

A ce genre, considéré comme une section du genre Andropogon, appartiennent deux especes de l'Inde, Amphilophis odorata, A. glabra, qui constituent quand elles sont jeunes un assez bon fourrage. A ce moment, le rapport $\mathrm{Ca} / \mathrm{P}$ est voisin de la normale, et après, les protéines et les cendres diminuent jusqu'à la maturité.

\section{Genre Andropogon}

A Madagascar, Andropogon trichozygus passe comme bonne espèce fourragère, sont également consommés: $A$. eucomus et $A$. madagascariensis.

Andropogon amplectens se rencontre aussi en Abyssinie, en Angola, en Afrique du Sud, avec de nombreuses variations ou formes.

Andropogon gayanus var. bisquamulatus forme avec ses touffes de $3-4 \mathrm{~m}$ de haut, l'essentiel des savanes qui, de la presqu'île du Cap Vert au Congo brûlent chaque année; la variété squamulatus est plus méridionale.

A. schirensis n'est intéressant que s'il est pâturé ou coupé avant floraison.

\section{Genre Brachiaria}

Brachiaria decumbens est estimé en Ouganda parce que la récolte est importante et que la prairie est belle en sol assez riche. Il résiste à la sécheresse; il y a diverses variétés locales; l'une d'elles forme un excellent couvert sur terrain ferrugineux et parait être excellente pour la prévention de l'érosion. Comparativement à Cynodon dactylon, $B$. decumbens est mieux accepté, mais moins bien que l'herbe à éléphant. La reproduction par graine est difficile, mieux vaut recourir aux boutures.

$B$. deflexa produit peu de fourrage mais est intéressant par sa résistance à la sécheresse:

B. dictyoneura, en Ouganda, qui se reproduit par stolons, forme quand elle est pâturée un tapis dense, résistant à la sécheresse. Or, on la reproduit difficilement par graines.

A. fulva est une bonne espèce (Ouganda) qui aime surtout le bord des mares.

B. Kotyschyana, espèce annuelle, répandue en Afrique orientale, est un bon fourrage, son rendement est moindre que celui de $B$. brizantha et $B$. decumbens.

$B$. platynota est comparable à $B$, brizantha. 
B. soluta est une bonne espèce, comparable à $B$. decumbens.

Au Soudan, en zone pluvieuse (plus de $700 \mathrm{~mm}$ ) Brachiaria obtusiflora; annuelle, produit beaucoup de fourrage apprécié.

\section{Genre Chrysopogon}

Chrysopogon acucilatus a été acclimaté en Côte d'Ivoire comme plante de couverture.

$C h$. aucheri var. pulvinatus et $C h$, aucheri var. quinquaplurius sont assez bonnes.

Chrysopogon aucheri existe aussi en Afrique orientale, ainsi que $C h$. aucheri var. pulvinatus.

\section{Genre Coelorachis}

Coelorachis afraurita est une espèce d'Afrique tropicale, pérenne, de faible valeur fourragère, aimant les terrains humides.

\section{Genre Dichantium}

Dichantium annulatum est une espèce pantropicale, subtropicale et même tempérée.

D. papillosum s'est montrée intéressante au Tanganyika; mais elle ne produit que 70 tonneshectare.

\section{Genre Erianthus}

Dans les parties montagneuses de l'Inde, Erianthus longisetoseus, Microstegium ciliatum, qui constituent le principal fourrage des herbivores sauvages sont aussi données au bétail. La première renferme, quand les pousses atteignent 1 mètre, 8 p. 100 de protéine; la deuxième 6 p. 100. La teneur est faible en $\mathrm{Ca}$ et $\mathrm{P}$.

Erianthus $=$ (Miscanthidium) flavescens et Er. violaceum sont des espèces africaines à peu près sans valeur.

\section{Genre Hackelochloa}

Hackelochloa granularis est une petite espèce annuelle, pantropicale, bonne espece fourragère, mais peu abondante.

\section{Genre Hemarthia}

Hemarthia altissima ( $H$. fasciculata) est, en Rhodésie, une des meilleures espèces des prairies humides sur sol noir; elle réussit aussi en terrain sec; on la propage par division de souches.

\section{Genre Hyparrhenia}

Le genre est bien représenté en Afrique orientale, où on trouve: $H$. barteri, $H$. bracteata, $H$. cymbaria, $H$. diplandra, $H$. dissoluta, $H$. familiaris, $H$. fustigiata,
H. filipendula, $H$. filipendula var. pilosa, H. finitima, $H$. hirta, $H$. lecomtei, $H$. lintonii, $H$, mobukensis, $H$. nyassae, $H$. pilgeriana, $H$. rufa, $H$. schimperi, $H$. snowdeni, $H$. variabilis.

\section{Genre Imperata}

Dans certaines régions du Queensland où, à l'abattoir on trouve souvent des calculs rénaux siliceux chez les bovins âgés, on attribue la présence de ces calculs à Imperata cylindrica var. major qui constitue dans ces régions un élément important des pâturages.

Quand on distribue à des bovins d'expérience répartis en deux lots, aux premiers une ration compusée d'un concentré et d'Imperata arundinacea, aux seconds, la même ration plus des cendres de bois, on observe que l'urine des premiers est acide. celle des seconds alcaline; la digestibilité est légèrement augmentée pour certains éléments de la deuxième ration.

Quand l'Imperata de pauvre qualité est donné comme seul aliment on n'observe pas d'autres accidents que ceux résultant de la déficience en protéine; la digestibilité de la cellulose augmente jusqu'à environ 74 p. 100.

\section{Genre Ischaemum}

Parmi les espèces de ce genre, Ischaemum rugosum s'est révélée intéressante dans l'Inde. A la floraison, cette herbe renferme, sur la matière sèche, 7,15 p. 100 de protéines brutes, 80,30 p. 100 d'hydrates de carbone et 10,07 p. 100 de cendres. Le taux de Ca est de 0,38, celui du phosphore, de 0,31 p. 100 . Le foin renferme 6,63 p. 100 de protéines brutes.

1. rugosum, à l'état vert, fournit un bilan positif à la fois pour le calcium et pour le phosphore; les animaux le consomment volontiers. D'autre part, elle fleurit au moment où les autres: herbes sont déjà ligneuses et donne un assez bon foin.

I. aristatum est aussi une assez bonne espece dans l'Inde. On lui reproche cependant de teinter le lait des vaches laitières; introduite à la Trinitad, elle y donne de bons résultats.

I. brachyatherum est mangée jeune, au Cameroun.

\section{Genre Iseilema}

sseilema laxum, dans l'Inde, a une valeur fourragère marquée, malgré son faible rendement; c'est que, parmi les espèces indigènes, elle a le plus fort rendement en protéines, extrait éthéré et matières minérales. 


\section{Genre Saccharum}

On estime dans l'Inde que les têtes de canne à sucre représentent un douzième du fourrage vert disponible, mais qu'elles sont mal utilisées. Leur substitution à d'autres fourrages n'en diminue pas la digestibilité, et, remplaçant une partie de tourteau, elles ne diminuent pas la production laitière.

Saccharum aegyptiacum peut être utilisé pour la fixation des dunes en Afrique du Nord.

\section{Genre Schizachyrium}

En Afrique tropicale, on rencontre Schizachyrium brevifolium qui existe aussi à Madagascar et donne un bon fourrage peu abondant; Sch. exile, dans la zone.soudanaise, estimé surtout quand il est jeune, Sch. pulchellum, du Sénégal au Congo.

\section{Genre Sorghum}

Sorghum alanum, quand il a $30 \mathrm{~cm}$, contient 14,6 p. 100 de protéine, il en contient encore 11 p. 100 au moment de la fenaison. Il est très apprécié des animaux comme foin et ensilage (Afrique du Sud).

A Madras, on a sélectionné une variété, A.S. 7657 de Sorghum roxburghii, qui possède un chaume succulent bien appété du bétail, et qui par rapport au chaume des variétés ordinaires renferme moins de cellulose, plus de glucides et de protéines. Par ailleurs le rendement en grains est plus grand.

Une variété blanche d'Andropogon sorghum (joli) cultivés dans l'Inde offre les variations suivantes entre 3 semaines et la floraison (matière sèche).

\begin{tabular}{|c|c|c|}
\hline & 3 semaines & Floraison \\
\hline Matières organiques . & 84,59 & 93,98 \\
\hline Protéine brute. & 29,93 & 9,93 \\
\hline Cellulose ......... & 24,44 & 38,50 \\
\hline Extr, non azoté & 26,22 & 44,22 \\
\hline Extrait éthéré & 4 & 1,33 \\
\hline Cendres $\ldots \ldots \ldots \ldots \ldots \ldots$ & 15,41 & 6,02 \\
\hline$\ldots \ldots \ldots \ldots \ldots$ & 1,06 & 0,36 \\
\hline$\ldots \ldots \ldots \ldots$ & 1,29 & 0,48 \\
\hline
\end{tabular}

Dans certaines régions d'Amérique (Oklahoma) on utilise une variété nouvelle de Sorghum sudanense où les chutes de pluies ne dépassent pas $889 \mathrm{~mm}$. Le rendement est légèrement inférieur, mais la proportion des feuilles dans le fourrage est plus forte par rapport aux tiges et le fourrage est plus appétissant.

Dans l'Inde, on recèpe $S$, vulgare dont on obtient deux coupes à deux mois ou deux mois et demi d'intervalle.
En Ouganda, on rencontre: Sorghum arund1naceum, bonne espèce; $S$. aterrimum, $S$. castaneum, $S$ : caudatum avec quatre variétés; $S$. dochna var. cerevisiae; $S$. guineense var, intermedia; $S$. nigricans, $S$. purpura-sericeum; $S$. rigidifolium, bonne espèce avant floraison; $S$. rigidifolium var, microstachyum; $S$, roxburghii var. hirsutum; $S$, verticilliflorum, bonne espèce pour' la pâture, l'ensilage, moins pour le foin.

\section{Genre Thelepogon}

Thelepogon elegans, annuel, peut constituer un pâturage moyen, mais serait amer.

\section{Genre Themeda}

Themeda tremula est; parmi de nombreuses graminées indigènes de l'Inde, celle qui donne les plus grands rendements.

\section{ARUNDINAE - BAMIBUSAE}

\section{Genre Phragmites}

On peut faire un bon ensilage avec des feuilles de Phragmites communis, En Afrique du Sud, planté dans les lits de rivière envasée il constitue un assez bon fourrage. Il est aussi utilisé pour la conservation de certains sols.

\section{Genre Arundo}

Dans diverses régions humides de l'Tnde, Arundo donax, bien que peu apprécié est parfois distribué, surtout quand les pousses ont 1 mètre de hauteur. A ce moment, elles contiennent $32 \mathrm{p} .100$ de matière sèche, 13 p. 100 de protéines brutes, dont 70 p. 100 sont digestibles.

\section{CHLORIDAE}

\section{Genre Chloris}

Les caractéristiques qui font recommander Chloris gayana pour la lulle contre l'érosion sonl les sui vantes: touffue, cette graminée a des racines fibreuses, tenaces et profondes qui lui permettent de supporter. la sécheresse. Ses stolons protègent bien le sol et assurent la multiplication et la permanence du peuplement. D'autre part, la: croissance a. lieu surtout en été; la plante est donc surtout adaptée aux régions oì les étés sont chauds et humides, mais elle résiste bien à la sécheresse el au froid.

Si elle préfère les terres franches, elle s'adapte à presque tous les sols, sauf les sols sableux ou forte- 
ment argileux. Elle accepte une forte alcalinité et, une fois établie, diminue le fendillement du sol. Les mois les plus favorables au semis sont les mois chauds et humides. On peut semer en même temps une légumineuse qui apportera de l'azote au sol et augmentera le rendement. En Australie on utilise de préférence Phaseolus lathyroides, Glycina javanica.

La tolérance au sel de Chloris gayana est indiquée par une expérience faite comparativement avec d'autres graminées, dans le Texas: Cynodon dactylon, Panicum ontidotale, Andropogon nodosus. C'est chloris gayana qui a le mieux résisté, son rendement n'étant pas affecté par des irrigations successives avcc do l'eau dont la teneur en sels était de 4,5 p. 100, dans un sol ayant une teneur en sels solubles atteignant 10 p. 100.

Dans les régions pluvieuses du Soudan, plus de $700 \mathrm{~mm}$, c'est Chloris gayana qui donna les meilleurs résultats parmi les espèces introdujtes, parce qu'elle tolère l'inondation et bien que la grande sécheresse lui soit dommageable, elle se rétablit dans le pâturage par semis naturel.

Chloris lamproparia existe aussi en. Afrique orientale et donne un bon fourrage en terrair-sec.

C. pycnothrix existe en Ouganda, en régions seches.

C. virgata est cultivé en Afrique du Sud et donne un bon foin.

\section{Genre Cynodon}

En Rhodésie, Cynodon pleptostachyum est la meilleure graminee fourragère dans les régions humides. Avec engrais azoté, on obtient 2 tonnes par acre (40 ares env.). Employé seul, le superphosphate n'a pas d'effet, mais l'addition de sulfate d'ammonium augmente la production et la teneur en protéine, cette teneur étant cinq fois plus importante que sans engrais. $C$. transvaalensis est très proche de $C$, dactylon et $C$. plectostachycum, mais généralement plus fort.

\section{Genre Microchloa}

Microchloa indica se rencontre aussi en Ouganda, où on la considere comme de faible valeur, ainsi que $M$. Kunthil (=M. abyssinica), très voisine.

\section{ERAGROSTAE}

\section{Genre Eragrostis}

Au cours des dernières années, en Afrique du Sud, pour les herbages d'été, Eragrostis curvula et le Sorghum alunum ont connu une vogue crois- sante; E. curvula, en pâturage temporaire, produit 4 à 5 tonnes de fourrage sec à l'hectare en deux coupes pendant lés mois d'été. Les deux graminées citées doivent jouer un rôle important dans les sols secs.

La teneur en protéine du foin d'E: curvula peut varier de 8,4 à 18 p. 100 , le dernier chiffre correspondant à la plante fumée au sulfate d'ammoniaque.

Parmi les nombreuses graminées d'Afrique du Sud expérimentées au Kenya, il n'en est guère que deux qui ont vraiment donné satisfaction: Eragrostis chloromeles et $E$. curvula.

La première, herbe pérenne, forme de grosses touffes avec de nombreuses feuilles à la base. Elle reussit bien dans la conservation des sols au Kenya.

$E$. curvula également pérenne, forme aussi de grosses touffes de 45 à $50 \mathrm{~cm}$ avec beaucoup de feuilles étroites à la base.

$E$. aspera se rencontre aussi en Afrique orientale, ainsi que $E$. blepharoglumis, de faible volume, E. chapellieri.

\section{Genre Leptocarydion}

A ce genre appartient Leptocarydion vulpiastrum, espèce annuelle résistante à la sécheresse (Ouganda) et recherchée pour son goût salé.

\section{ORYZEAF}

\section{Genre Leersia}

La dessiccation de Leersia hexandra n'amene qu'une faible perte des fractions digestibles, notamment des protéines. Le foin garde une belle coloration verte; donné à raison de $0,500 \mathrm{~kg}$ de protéines, pour $1.000 \mathrm{~kg}$ de poids vif, le vert ou le foin semble assurer un bilan azoté positif, les bilans calciques et phosphorés étant négatifs.

\section{Genre Oryza}

La paille de riz renferme parfois 15 p. 100 de cendres (sur la matière sèche) dont $2 / 3$ de silice. Pour la donner aux bovins, on conseille de la mêler à 3 ou 4 fois son poids de luzerne ou d'une autre légumineuse.

On peut aussi l'ensiler avec addition d'un acide minéral. Un tel ensilage, au bout de 100 jours, a la composition suivante:

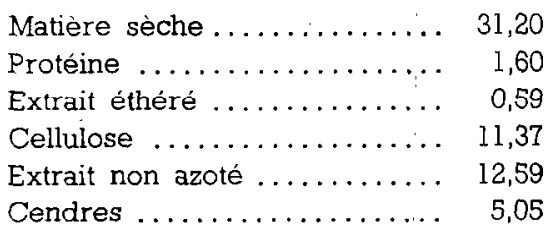




\section{PANICEAE:}

\section{Genre Acroceras}

On a nourri, pendant un temps déterminé, des mérinos d'Afrique du Sud, répartis en trois lots, respectivement avec du foin de brousse, du foin de Paspalum urvillei, du foin d'Acroceras macrum. C'est ce dernier foin qui est consommé le plus volontiers et les animaux gagnent du poids, alors qu'ils en perdent avec les deux autres foins; cela tient à ce que le foin d'Acroceras est plus riche en protéine plus tendre, moins lignifié.

\section{Genre Brachiaria}

Brachiaria glabra existe non seulement en Afrique occidentale (Sénégal) mais aussi à Madagascar, en Australie, dans l'Inde; c'est une bonne espèce.

B. distichophylla est une petite espèce d'Afrique occidentale, du Congo, surtout mangée par les moutons. Au Congo belge elle est mangée par les hippopotames.

A Madagascar en zones assez humides, on trouve $B$. distachya volontiers mangée; dans les lieux humides, les cours d'eau, $B$. mutica, bon fourrage vivace, stolonifère, renfermant plus de 9 p. 100 de protéines.

\section{Genre Cenchrus}

Cenchrus ciliaris existe dans toute l'Afrique tropicale sèche, Mozambique, Madagascar, Congo belge, Sud-Est de l'Europe, Nord-Est des Indes.

\section{Genre Digitaria}

Digitaria perrotetii existe du Sénégal au Sud de I'Afrique tropicale. Les moutons surtout l'apprécient. A Hawaï, on a beaucoup utilisé $D$. decumbens qu'on reproduit par stolons, après épandage d'un engrais phosphaté. On obtient 125 tonnes de vert à l'hectare.

\section{Genre Eriochloa}

Eriochloa nubica (= acrotricha) se rencontre aussi en zones sèches en Ouganda, et s'y montre un bon fourrage. En zones humides on trouve aussi E. procera (=E ramosa).

\section{Genre Melinis}

C'est un mois avant la floraison, que Melinis minutiflora a la meilleure composition; on abserve en effet les différences suivantes entre des foins obtenus avant ou pendant la floraison:

\begin{tabular}{|c|c|c|}
\hline & $\begin{array}{c}\text { Avant } \\
\text { floraison }\end{array}$ & $\begin{array}{l}\text { Pendant } \\
\text { floraison }\end{array}$ \\
\hline Protéines & 4,38 & 4,19 \\
\hline Extrait éthéré & 1,02 & 1,12 \\
\hline Hydrates de carbone ....... & 85,77 & 84,55 \\
\hline Cendres $\ldots \ldots \ldots \ldots \ldots \ldots \ldots$ & 8,83 & 10,14 \\
\hline$\ldots \ldots \ldots \ldots$ & 0,54 & 0,37 \\
\hline$\ldots \ldots \ldots \ldots \ldots$ & 0,31 & 0,29 \\
\hline
\end{tabular}

\section{Genre Panicum}

Au Queensland, où Panicum maximum existe à l'état sauvage on a sélectionné pour la culture trois variétés. $P$. maximum var. typica, $P$. maximum var. trichiglume, $P$. maximum var. coloratum; toutes poussent en touffes de plusieurs pieds de haut couvrant bien le sol, les feuilles partant à la fois du centre et de la périphérie de la touffe. Les meilleurs résultats ont été obtenus avec la variété trichoglume, cultivé en lignes avec de la luzerne (sur sols alluviaux).

Dans l'Inde, le meilleur rendement de $P$, maximum eșt obtenu avec des coupes mensuelles (pour Pennisetum purpureum, il est préférable de couper tous les 50 jours).

En Afrique orientale (Ouganda) le genre est largement représenté. Aux espèces citées, on peut ajouter $P$. adenophorum (montagnes), $P$, atrosanguineum (de peu de valeur). $P$. brevifolium, $P$. calvum (forêts), $P$. chionachne (lieux humides), $P$. coloratum var. minus (régions sèches), $P$. deustum (mangé jeune), $P$. dregeanum (bonne espèce), $P$. eickii (lieux humides), P. flocciflorum (marais), $P$. fulgens (peu de valeur), $P$. flavescens (bonne espèce des lieux humides), P. heterostachyum, P. hochstetteri (montagnes), $P$. infestum (lieux humides), $P$, kisantuense (marais), P. massaiense, P. meyerianum, P. monticolum, P. parvifolium, P. porphyrrhizon, $P$. pubiglume, $P$. repens (bonne espèce des terrains sablonneux, bord des cours d'eau), $P$. robynsii (forêts), $P$. snowdenii, $P$. trichocladum (considéré en Ouganda comme une des meilleures espèces aussi bien en vert que sec ou ensilé).

\section{Genre Paspalum}

Ies caractéristiques climatiques générales de Paspalum dilatatum, maintenant répandu dans de nombreux pays tropicaux et subtropicaux et utilisé comme herbage dans certains pays tempérés, sont les suivantes: une saison chaude et humide, la plante étant à croissance estivale; le sol, s'il est trop pauvre, doit recevoir des engrais. Sauf dans des cas très favorables, le pâturage est formé de cette seule espèce, sans légumineuse. Les pâturages peu vigoureux risquent l'envahissement 
d'autres espèces, mais dans certaines conditions de sol et de pluviométrie, on peut réussir un mélange d'espèces.

Les essais sur la digestibilité de Paspalum dilatatum, à des stades différents de végétation, chez des vaches laitières, montrent que tous les éléments sauf la matière grasse voient leur digestibilité diminuer régulièrement à mesure que la plante va vers la maturité. On observe les différences suivantes dans le coefficient de digestibilité:

\begin{tabular}{|c|c|c|}
\hline & Plante jeune & Plante mûre \\
\hline Matière organique .. & 78,1 & 58,3 \\
\hline Protéine. & 75,7 & 39,4 \\
\hline Extrait éthéré & 57,3 & 37,3 (avec de \\
\hline & \multicolumn{2}{|c|}{ violentes fluctuations) } \\
\hline Cellulose & 80,8 & 63,9 \\
\hline Extractif non azoté & 78,8 & 57,5 \\
\hline
\end{tabular}

Paspalum notatum, moins recherché des animaux et répandu au Congo belge et au Moyen Congo, s'oppose au ravinement et à la propagation des incendies.

\section{Genre Pennisetum}

Dans l'Inde (Bihar) on a recours à Pennisetum pedicillatum à la fois comme fourrage et plante de conservation du sol.

Au Tanganyika, avec une variété glabre de Pennisetum purpureum on a obtenu en irrigant et pendant une période de quatre ans une moyenne de $250 \mathrm{t} / \mathrm{ha}$, en 6 coupes; en même temps, la luzerne ne donnait que $90 \mathrm{t} / \mathrm{ha}$; par ailleurs alors que, très jeune $(30 \mathrm{~cm})$ l'herbe à éléphant a la même valeur que la luzerne, la diminution est rapide.

Au Kenya, des essais pour la production de fourrage de saison sèche avec Pennisetum purpureum ont donné $5,2 \mathrm{t}$ en janvier et $7,7 \mathrm{t}$ en novembre. Il répond bien au fumier de ferme et au phosphate; en le cultivant avec des légumineuses, on compense sa faible teneur en protéines.

$\mathrm{Si}$ on détermine la composition du Pennisetum purpureum à des stades différents de 6 à 15 semaines on observe que, avec l'âge, la cellulose augmente alors que les éléments digestibles totaux et la protéine diminuent; le rendement annuel en éléments digestibles totaux et en protéine digestible est respectivement de 4,6 tonnes et 722 livres par acre $(808 \mathrm{~kg} / \mathrm{ha})$ à 6 semaines et 10,36 tonnes et 597 livres (668 kg/ha) à 14 semaines.

$\mathrm{Si}$ on distribue à des vaches pendant 12 semaines une ration renfermant 10,20 et 30 kilogrammes de Pennisetum, on obtient respectivement 23,8 et 21,7 et 20,6 litres d'un lait à $40 \mathrm{gr}$ de beurre.
La farine de Pennisetum purpureum, l'herbe ayant été récoltée 3 ou 4 semaines après une première coupe, peut sans inconvénient remplacer la, farine de luzerne dans une pâtée pour poussins au taux de 5 p. 100.

En Tunisie où Pennisetum merkeri réussit en raison de sa résistance à la sécheresse, 'des essais sur le mouton et des analyses ont donné les résultats suivants (chiffres pour $100 \mathrm{gr}$ de matière sèche, la teneur en matière sèche étant de 18,18 p. 100):

\begin{tabular}{|c|c|c|}
\hline & $\begin{array}{l}\text { Pourcentage sur } \\
\text { matière sèche }\end{array}$ & $\begin{array}{l}\text { Coefficients } \\
\text { de digestibilité }\end{array}$ \\
\hline Matic̀res azotées & 10,89 & 64,58 \\
\hline Matières grasses & 6,71 & 68,95 \\
\hline Extractif non azoté . & 44,68 & 57,75 \\
\hline Cellulose....$\ldots \ldots \ldots$ & 29,42 & 43,17 \\
\hline Lignine $\ldots \ldots \ldots \ldots$ & 13,36 & 37,17 \\
\hline Glucides hydrosolubles. & 2,57 & 59,04 \\
\hline Pentoses ............ & 0,40 & 65,69 \\
\hline Pentosanes ........ & 0,35 & 65,51 \\
\hline Matières minérales .... . & 8,30 & 6,31 \\
\hline
\end{tabular}

En Afrique orientale (Ouganda), on trouve aussi: Pennisetum catabasis, en grosses touffes, surtout au bord des eaux; $P$. giganteum, à port de bambou, et atteignant $5 \mathrm{~m}$, mangé jeune, en zones humides et terrains profonds; $P$. glabrum, espèce de montagne; $P$. mildbraedii, qui pousse en altitude est recherché des buffles et se montre assez résistant à la coupe et à la pâture; $P$. ramosum, bonne espèce à l'état jeune, $P$. trachyphyllum, surtout en altitude, où il constitue un bon fourrage.

\section{Genre Rhynchelytrum}

En Ouganda, on considère que Rhynchelytrum repens peut pousser et donner un bon couvert végétal dans de mauvaises conditions, ce qui permet son emploi pour la régénération des sols usés. On le rencontre sur des terrains pauvres non cultivés depuis longtemps, mais aussi sur. les jachères récentes.

\section{Genre Sacciolepis}

En Afrique orientale, Sacciolepis africana est recherché par le bétail. On rencontre aussi $S$. auriculata, espèce des marais, comme $S$. johnstonii.

\section{Genre Setaria}

En Afrique orientale (Ouganda), on rencontre Setaria aequalis, de peu de valeur fourragère; $S$. acromeloena, $S$. caudula (forêts), $S$. ciliolata, $S$. chevalieri, considérée comme une bonne espèce, mais meilleure pour la coupe que pour la pâture; $S$. holstii, bon fourrage à l'état jeune; $S$. incrassata 
(surtout sur les terres à coton); $S$. kagerensis; $S$. longiseta, appréciée du bétail et donnant un bon foin; S. orthosticha; S. pallidifusca, et S. pallidifusca forma penecillata, excellent fourrage mais de faible prcduction, $S$. sphacelata, très répandu en certaines régions soumises au pâturage intensif et aux feux de brousse. (Il existe deux variétés bien distinctes par leur habitat et leur, aspect, l'une est en touffes et à inflorescence dorée; l'autre à inflorescence verte et n'est pas en touffes. La seconde est préférable pour réaliser un couvert continu); $S$. splendida (montagnes); $S$. trinerva; $S$. verticillata, bonne espèce à l'état jeune, majs parfois envahissante dans les cultures.

Setaria splendida, au Tanganyika se présente comme une herbe feuillue, succulente, dont le rendement peut se rapprocher de celui de Pennisetum purpureum, Setaria sphavelata est moins productif, mais a l'avantage de se reproduire par graines. Il atteint $1,80 \mathrm{~m}$ et peut être pâturé, fané ou ensilé. Le rendement moyen est de 150 tonnes (ha). Une variété « Nondi Setaria » donne des résultats très prometteurs.

\section{Genre Urochloa}

En Afrique oricntalc, on trouvc Urochloa balbodes, excellente espèce, et $U$. panicoïdes qui fournit un fourrage succulent, mais éphémère.

\section{PAPPOPHOREAE}

\section{Genre Enneapogon}

Confondu avec le genre Pappophorum, ce genre comprend des espèces américaines et australiennes qui constituent un fourrage de médiocre valeur sur les dunes sablonneuses. En Nouvelles Galles du Sud, des Enneapogon sont utilisés pour fixer les sables d'origine éolienne après une première colonisation par le « silver grass », Schismus barbatus, et diverses composées. En Afrique orientale (Ouganda), E. cenchroïdes serait une bonne espèce.

\section{PHALARIDEAE}

\section{Genre Phalaris}

Phalaris arundinacea est considérée aux U.S.A. comme parfaitement adapté à la lutte contre le ravinement, en raison de sa vigueur, de son haut rendenent el du fait qu'il reste verl en élé. Il faul soigner la préparation du terrain, les engrais à employer, la profondeur du semis; mais les meilleurs résultats sont obtenus avec les éclats de souche.

On utilise aussi cette graminée pour protéger les bords des mares, les berges des canaux.

Les accidents causés par Phalaris tuberosa chez. le mouton sont des troubles nerveux (staggers).' L'administration fréquente de petites doses de cobalt les évite, probablement parce qu'elles accroissent la production de vit. $\mathrm{B}_{12}$ dans l'organisme et permettent la destruction plus rapide des substances toxiques de la plante.

\section{SPOROBOLAE}

\section{Genre Sporobolus}

Sporobolus arabicus, dans l'Inde, fournit un foin dont la valeur égale celle de diverses graminées cultivées pour leur foin. La digestibilité offre les coefficients suivants (chez le bœuf): protéine brute, 42; extrait éthéré 41; hydrates de carbone, 43; 100 kilogrammes de foin renferment environ $2,6 \mathrm{~kg}$ de protéine brute, $40 \mathrm{~kg}$ d'éléments digestibles totaux.

\section{VII. - LÉGUMINEUSES}

\section{Légumineuses à fins diverses}

En Guinée, dans les bananeraies, après divers essais de légumineuses de couverture, on n'a retenu que Desmodium ovalifolium et Pueraria javanica (phaseoloïdes).

Au Kenya, les légumineuses destinées à la conservation du sol en altitude moyenne sont Rhynchosia minima, Glycine javanica, Dolichos spp.

En Malaisie, dans les plantations d'Hévea, les plantes rampantes les plus utilisées sont: Centrosema pubescens, Pueraria phaseoloïdes, Calopogonium mucunoídes.
Glycine javanica, en Afrique du Sud, est une bonne espèce conservatrice du sol.

Dans les plantations de palmier Fiaeis, Pteraria javanica est une bonne plante de couverture. $P$. javanica est utilisé, à Ceylan, concuremment avec Centrosema pubescens. On y a aussi recours à Crotalaria striata, C. anagyroïdes, C. usaramensis, C. juncea, Calopogonium mucunoides, Tephrosia candida, comme engrais verts.

Une variété inerme de Mimosa indica est'considérée comme un des meilleurs engrais verts tropicaux. 
Le plus employé des engrais verts dans l'Inde est Crotalaria juncea; on utilise aussi $C$. striata, C. verrucosa.

C. striata est robuste, résistant aux pluies, adapté aux sols sablonneux côtiers. C. junçea a une croissance rapide, abondante, et se contente de sols pauvres.

En Guinée, on peut utiliser Indifogera arrecta, Cassia alata, Desmodium ovalifolium.

A Madagascar, dans la culture du riz' l'engrais vert qui donne le plus fort rendement est le soja, vient ensuite le Cajanus indicus.

\section{Qualites : des légumineuses}

Des ensilages de trois léguminetises cultivées à Madagascar ont la composition suivante:

\begin{tabular}{|c|c|c|c|}
\hline & $\begin{array}{c}\text { Mucuna } \\
\text { ptilis }\end{array}$ & $\begin{array}{c}\text { Vigna } \\
\text { sinensis }\end{array}$ & Soja \\
\hline 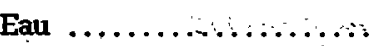 & $51 ; 52$ & 50.45 & 50,30 \\
\hline rotides & 4,86 & 10,55 & 3,8 \\
\hline$\ldots \ldots \ldots \ldots \ldots$ & 3,09 & 1.46 & 1,40 \\
\hline Cellulose & 28,98 & 16,09 & 9,57 \\
\hline Glucides . & 6,33 & 9,01 & 7,2 \\
\hline Cendres & 6,22 & 12,44 & 7,67 \\
\hline g p. $100 \mathrm{~g}$ & 250 & 439 & 445 \\
\hline hosphore & 103 & 116 & 146 \\
\hline
\end{tabular}

Lès foins de divers fourrages cultivés au Brésil ont la composition suivante, ce qui indique les différences entre les foins de graminées ou de légumineuses.

$$
\begin{gathered}
\text { Proteine Extrait Cellulose Extr. non Cendres } \\
\text { othoré }
\end{gathered}
$$

$\begin{array}{llllll}\text { Cynodon dactylon .... } & 5,81 & 1,58 & 22,29 & 55,03 & 5,21\end{array}$

(à la floraison)

$\begin{array}{llllll}\text { Panicum maximum.... } & 11,83 & 2,27 & 23,42 & 44,48 & 8,93\end{array}$ (avant floraison)

$\begin{array}{lllll}\text { Axonopus compresses. } \quad 9,38 \quad 2,09 & 16,01 \quad 57,63 & 5,74\end{array}$ (début de floraison)

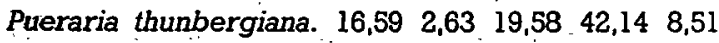
(jeune)

\section{Genre Acacia}

Acacia beilandieri est une espèce buissonneuse qui abonde dans certaines zones d'élevage du mouton, au Texas. Mangée trop abondamment en saison sèche, elle cause des accidents d'ataxie et même la mort; mais la guérison survient ordinairement quand on met les animaux à un autre régime.

\section{Genre Alysicarpus}

Alysicarpus violaceus, semi-herbacée, est consommée dans les terres cultivées au Cameroun, et mangée à l'état adulte; elle pourrait y être cultivée.

\section{Genre Arachis}

Du foin d'arachide (Afrique du Sud) avec ou sans les gousses est moins riche en proténe mais aussi en cellulose que d'autres foins de légumineuses.

La cellulose est plus digestible que celle du foin de luzerne. La teneur en protéine varie considerablement, surtout sous l'effet de la pluie qui cause des pertes.

\section{- Genre Clitoria}

Au Soudan, en région pluvieuse, on a cultivé en association Clitoria terneata et Rhodes grass, en terrain inondé à la saison des pluies. La croissance a ét’́ bonne sauf aux endroits trop humides.

\section{Genre Daniella}

Daniella oliveri a de jeunes feuilles, que les ruminants consomment au Cameroun, dans les galeries forestières, au bord des mares.

\section{Genre Desmodium}

Desmodium ovalitolium est utilisé comme plante de couverture dans les plantations de the.

Les farines de feuilles de soja (1) et de Desmodium (2), cultivés à Madagascar, ont respectivement la composition suivante:

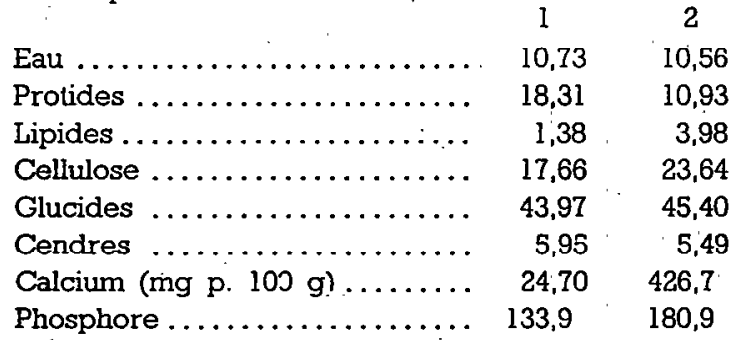

\section{Genre Eriosema}

Eriosema procumbens. E. cajanoides sont en général délaissés ou peu appréciés des zébus, à Madagascar.

\section{Genre Gliciridia}

Glicindia maculata cultivée comme engrais vert en diverses régions, a des feuilles que le bétail accepte en Malaisie, à Ceylan, aux Indes occidentales, alors "qu'il les refuserait à Madras, en raison de la présence d'un composé phénolique. 
Leur composition, pour 100, est la suivante:

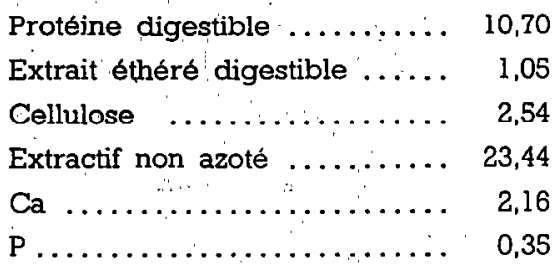

Dans les cocoteraies, le rapport peut être de $5,500 \mathrm{~kg}$ à l'hectare.

\section{Genre Glycîne}

Quand on alimente des lapines avec une ration renfermant environ 50 p. 100 de foin de soja; on observe des accidents que ne causent pas d'autres fourrages, notamment le foin de Lespedeza : stérilité partielle, mortinatalité, résorptions fcetales, il y a souvent: aussi des hémorragies, des lésions gastriques, des parésies.

Glycine borianii offre de grandes promesses en zone pluvieuse du Soudan, en association avec des graminées.

\section{Genre Herminiera}

Herminiera elaphroxylon dans les prairies inondées a des feuilles mangées par les ruminants.

\section{Genre Indigofera}

A la Trinidad, divers Indigofera, dont $I$. endecaphylla, I. subulata donnent des résultats peu intéressants, comparés à Pueraria javanica et Calopogonium mucunoîdes.

Indigofera hersuta en Floride cause des accidents par ses poils.

L'intoxication par I. endecaphylla chez le poussin ne. se produit que si on incorpore 10 p. $100 \mathrm{du}$ fourrage à la ration; elle peut se traduire seulement par un retard de croissance. Chez le cheval, on peut reproduire la "maladie de Birdsville » en donnant $5 \mathrm{~kg}$ de plante frajiche pendant un minimum de 2 semaines. Ávec des quantités plus importantes, on obtient des symptômes au bout de 10 jours.

La vitamine $B_{1}$ n'a pas, d'effet curatif.

On a observé, à Ceylan, que chez des veaux recevant pendant deux semaines une ration comprenant $10 \mathrm{~kg}$ de graminées et $5 \mathrm{~kg}$ d'Indigofera endecaphylla, surviennent des symptômes qui marquent l'atteinte du foie et des reins.
Indigofera, subulata offre des promesses inté ressantes, en zone pluvieuse du Soudan en association avec des graminées.

\section{Genre Isoberlinia}

Isoberlinia doka dans les massifs montagneux du Cameroun, a des feuilles mangées par les rưminants.

\section{Genre Leucaena}

La mimosine des feuilles de Leucaena glauca résiste à la dessiccation: par contre, elle est fortement diminuée par la chaleur humide à $70^{\circ} \mathrm{C}$; la toxicité est également réduite par l'addition de sulfate de fer (à $3 p, 100$ ) aux feuilles fraiches. Les graines voient également leur toxicité diminuée par la chaleur humide. On admet parfois que la mimosine est détnuite dans le rumeri. Ce n'est pas le cas dans les essaís réalisés au Congo belge chez le mouton; elle cause une violente cystite hémorragique et la chute de la läine.

\section{Genre Lonchocarpus}

Lonchocarpus laxifloris, assez race dans les galeries forestières du Cameroun, a des feuilles mangées par le bétail.

\section{Genre Lupinus}

Le lupin doux, non toxique, a donné d'excellents résultats au Katanga; on obtient plus de 50 tonnes de vert à l'hectare, soit environ 8,500 $\mathrm{t}$ en sec et $1,500 \mathrm{t}$ de protéine. La plante a un système radiculaire profond, ce qui lui permet de résister à la sécheresse et de se nourrir en profondeur. Elle peut réussir dans les sols sableux acides où les graminées sélectionnées ne peuvent réussir.

\section{Genre Medicago}

De façon générale, l'herbe de prairie renferme moins de carotène que la luzerne, mais comme la dessiccation "est plus rapide lors de la fenaison, la perte en carotène est moindre, et il arrive que du foin de graminées renferme trois fois plus de carotène que du foin de luzerne.

On contrarie la perte en carotène de la farine de luzerne par l'addition de diverses substances en poudre. Les tourteaux de soja ou de coton par pression doublent le temps que mettent à disparaitre $50 \mathrm{p}, 100 \mathrm{du}$ carotène. Une bonne protection est également fournie par le son de riz. Mais les tourteaux par extraction ont peu d'effet, et le tourteau de lin accélère l'altération. La proportion de tourteau 
de soja par rapport à la luzerne n'est active que quand elle dépasse $1 / 5$, ce qui constitue un minimum. On peut aussi réduire la perte de carotène à $10 \mathrm{p} .100$ en ajoutant à la farine 5 p. 100 d'huile végétale, animale ou minérale.

Les essais chez le veau montrent que la luzerne séchée artificiellement est mangée mieux, assure une croissance plus rapide et fournit plus de vitamine $A$ que la luzerne séchée naturellement.

L'expérimentation sur des truies semble indiquer que la luzerne favorise la multiplicité des naissances; d'ailleurs en sacrifiant les truies en expérience, on trouve chez elles un plus grand nombre de corps jaunes que chez les témoins; la luzerne favoriserait le taux d'ovulation.

Quand, dans la ration destinée à des poussins, on dépasse 5 p. 100 de farine de luzerne, on observe une baisse de croissance; le facteur incriminable est organique, puisqu'il n'existe pas dans les cendres ; il peut être extrait à l'eau chaude, à l'alcool, d'où on peut le précipiter par l'acétone. Il est hémolytique et paraît être une saponine, son action pouvant être contrariée par l'addition du cholestérol à la ration.

Chez des vaches auxquelles on donne $15 \mathrm{~kg}$ de foin de luzerne plus un concentré (12 p. 100 de protéine) ou $15 \mathrm{~kg}$ de foin d'arachide avec un concentré (20 p. 100 de protéine), le foin de luzerne fournit plus de lait et une plus forte proportion de matière grasse et de solides non gras, mais les vaches maigrissent. Avec le foin d'arachide, pas de perte de poids, mais il est moins bien accepté et a un effet purgatif.

Chez les porcs à l'engrais, 5 parties de farine de luzerne peuvent être remplacées par 15 parties de farine d'arachide, proportion qu'il faut diminuer si les gousses sont encore adhérentes, sinon on obtient un lard mou. Chez les vaches, il faut prendre la même précaution si on veut éviter la diarrhée.

Diverses plantes des régions chaudes ont des feuilles qui peuvent remplacer la farine de luzerne dans l'alimentation des volailles.

En effet, on a fabriqué une poudre de feuilles pour poussins avec des feuilles de Desmodium, de Kikuyu, de ramie et de bananes (feuilles séchées, à l'air chaud à $40^{\circ}$ ). La teneur respective en protéine, cellulose et cendres était de:

\begin{tabular}{|c|c|c|c|}
\hline & Protéine & Cellulose & Cendres \\
\hline Desmodium & 12.9 & 20,7 & 7,4 \\
\hline Kikuyu & 16,3 & 14,0 & 9, \\
\hline Ramie. & 22,4 & 11,9 & 17 \\
\hline Banane $\ldots \ldots \ldots \ldots \ldots$ & 16,1 & 16.6 & 12 \\
\hline
\end{tabular}

L'analyse montre que ces farines sont égales ou supérieures à des farines de luzerne moyennes, en ce qui concerne la teneur en caroténoides, Vit. $B_{1}$, riboflavine et acide nicotinique. C'est la farine de feuilles de banane qui est la plus riche en riboflavine.

L'emploi de ces farines incorporées à la ration jusqu'à une proportion de 20 p. 100 se révèle favorable.

Le traitement de la farine de luzerne par un antioxydant mêlé à une huile végétale, à la concentration de 0,125 p. 100 , évite la perte d'une forte proportion de carotène.

A Chypre, dans des conditions climatiques assez rudes $\left(42^{\circ} \mathrm{C}\right.$ en saison sèche, 350 à $550 \mathrm{~mm}$ de pluie), Medicago tribuloides réussit bien.

\section{Genre Ornithopus}

La serradelle offre des perspectives intéressantes dans le Sud-Ouest de l'Afrique du Sud.

Au moment de la floraison, la composition est la suivante:

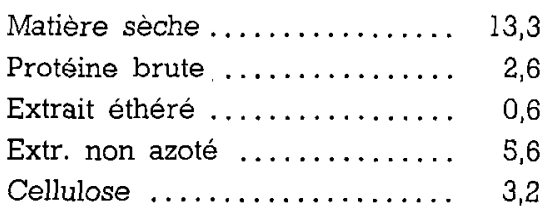

\section{Genre Phaseolus}

Phaseolus aconitifolius, cultivé comme engrais vert à Madras, est aussi considéré comme un bon fourrage.

Coupé à environ trois mois d'intervalle, il a la composition moyenne suivante, pour 100 de matière sèche:

$\begin{array}{lrr}\text { Protéines } \ldots \ldots \ldots \ldots \ldots \ldots \ldots \ldots & 23,91 \\ \text { Extrait éthéré } \ldots \ldots \ldots \ldots \ldots \ldots \ldots & 2,76 \\ \text { Cellulose } \ldots \ldots \ldots \ldots \ldots \ldots \ldots \ldots & 16,57 \\ \text { Extr. non azote } \ldots \ldots \ldots \ldots \ldots \ldots & 43,56 \\ \text { Cendres } \ldots \ldots \ldots \ldots \ldots \ldots \ldots \ldots \ldots & 13,02 \\ \text { Ca } \ldots \ldots \ldots \ldots \ldots \ldots \ldots \ldots \ldots & 1,57 \\ \text { P } \ldots \ldots \ldots \ldots \ldots \ldots \ldots \ldots & 0,50\end{array}$

La valeur nutritive égale celle du foin de luzerne, mais, en raison du rapport $\mathrm{Ca} / \mathrm{P}$, il faut supplémenter avec un produit riche en $\mathrm{P}$, comme le son.

Phaseolus lathyroides a été recommandé pour les sols sableux du Queensland (il doit être mouillé avant d'être semé). Pour ces sols on recommande aussi de l'associer à des graminées comme Chloris gayana, Panicum maximum, Pennisetum ciliare, Melinis minutiflora. 
A Ceylan, on utilise volontiers les Phaseolus comme engrais vert: $P$. aconitifolius, $P$. mungo, $P$. mungo radiatus, $P$. trilobus.

Dans l'Inde (Bihar) on cultive $P$, ricciardum, seul ou associé au Sorgho.

\section{Genre Pterocarpus}

Une analyse des feuilles de Pterocarpus erinaceus, comparativement à celle que nous avions donnée, fournit les chiffres suivants:

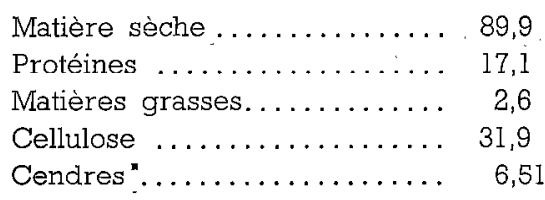

\section{Genre Pueraria}

Pueraria phaseloïdes $:=P$. javanica a été introduit à Madagascar il demande au moins $150 \mathrm{~mm}$ d'eau, et la température ne doit pas tomber au-dessous de $10^{\circ}$. On peut le semer avec Melinis minutiflora, Panicum maximum, maüs.

\section{Genre Richardia}

Le « trèfle mexicain », Richardia bresiliensis, contient 73 p. 100 d'eau, et, sur la matière sèche:

\begin{tabular}{|c|c|}
\hline Protéine & 21,3 \\
\hline Extrait éthéré & 1,9 \\
\hline Ccllulose ....... & 25,5 \\
\hline Extr. non azoté & 38 \\
\hline Nondros & 13 \\
\hline
\end{tabular}

Les cendres renferment 49 p. 100 de Ca et 0,8 p. 100 de $\mathrm{P}_{2} \mathrm{O}_{5}$. La plante hachée est bien acceptée des volailles.

\section{Genre Sesbania}

A Madagascar, Sesbania pubescens, fréquent dans les endroits frais, le lit des rivières, a un feuillage bien appété des bovins.

Dans l'Inde, on utilise comme engrais vert: $S$. aculeata dans les sols lourds, marécageux, salins: $S$, aegyptiaca également dans les terrains marécageux et dans les terres acides des plantations de the de l' $\Lambda$ ssam. On l'y considère aussi comme un bon fourrage et une bonne plante à fibre.

On a essayé de distribuer comme fourrage Sesbania speciosa, cultivé en Amérique puis dans l'Inde comme engrais vert. Les animaux le refusent habituellement. La composition de la plante à 5 mois, cst la suivante, pour 100 de matière sèche (feuilles).

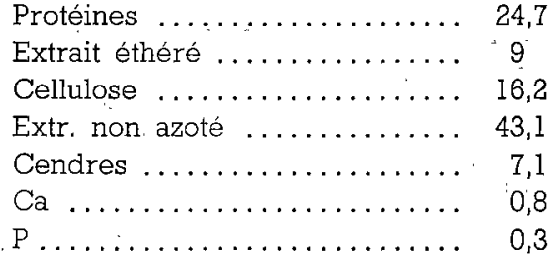

\section{Genre Stylosanthes}

Essayé au Congo Belge, Stylosanthes gracilis $s^{\prime} y$ est montré un fourrage de grande valeur, malgré la déficience en méthionine et cystine. La composition et les coefficients de digestibilité sont les suivants :

$\begin{array}{llccc} & \begin{array}{c}\text { Matière } \\ \text { Inaíche }\end{array} & \begin{array}{c}\text { Matière } \\ \text { sèche }\end{array} & \begin{array}{c}\text { Coef. } \\ \text { digest. }\end{array} \\ \text { Protéine. } \ldots \ldots \ldots \ldots \ldots \ldots \ldots & 18,11 & 20,06 & 64,63 \\ \text { Extrait éthéré } \ldots \ldots \ldots \ldots \ldots & 18,67 & 20,68 & 40,15 \\ \text { Cellulose } \ldots \ldots \ldots \ldots \ldots \ldots & 26,37 & 29,21 & 66,75 \\ \text { Extractif non azoté } \ldots \ldots \ldots & 28,83 & 21 & 59,39 \\ \text { Cendres } \ldots \ldots \ldots \ldots \ldots \ldots \ldots & 8,02 & 8,71 & 38,33\end{array}$

\section{Genre Tetragonolobus}

En Israël, on cultive Tetragonolobus palestinum, qui donne $4.800 \mathrm{~kg}$ de foin à l'hectare et jusclu'à $1.400 \mathrm{~kg}$ de graines. Le foin égal en qualité celui de Vicia sativa et le rendement est plus grand.

\section{Genre Trifolium}

La valeur nutritive et la digestibilité du Trifolium alexandrinum cultivé dans le climat sec de Sicile, sont estimées ainsi que suit:

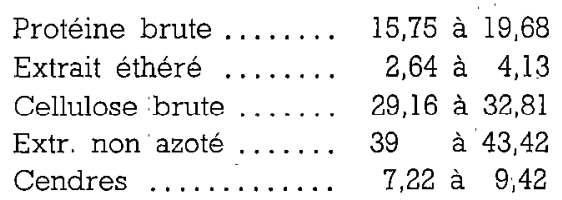

La matière sèche est en moyenne de 17,92. Les coefficients de digestibilité sont de 66,94 à 70 pour la protéine; 47,63 à 50,84 pour l'extrait éthéré, 49,79 à 52,43 pour la cellulose, '68,29 à 71,43 pour 'l'extractif non azoté. Un kilogramme de matière sèche correspond à 0,52 unité fourragère.

En Israël, on a tenté la cuituré de divers trèfles sauvages. Certains se sont montrés sans intérêt: Tr. lappaceum, Tr. campestre, Tr. resupinatum; d'autres par contre, ont donné des résultats prometteurs: Tr. clypeatum, Tr. spumosum, Tr. purpureum, Tr. carmelii.

Le Trifolium subterraneum est devenu la base des pâturages améliorés dans l'Australie du Sud; 
mais il faut maintenir l'équilibre entre cette légumineuse et les graminées, et éviter l'envahissement des mauvaises herbes. Sur les sols pauvres, une application de superphosphate permet une pousse vigoureuse et la végétation des graminées reste médiocre; cela facilite l'édification de la fertilité du sol. Si le trèfle continue à dominer, une réduction du superphosphate ne diminue pas la proportion des légumineuses, probablement parce qu'elles amènent une teneur en azote insuffisante pour les graminées.

On trouve de la génistéine (la substance oestrogène de $T$. subterraneum) dans tous les échantillons de Tr. subterraneum, qu'ils soient d'Australie ou de la région méditerranéenne. Dans les autres esł èces (Tr. pratensis, trefle rouge, Tr. campes- tris), la proportion est moindre, alors qu'elle est aussi grande dans $T$. globosum.

\section{Genre Trigonella}

Le meilleur moment pour faner Trigonella foenum graecum est vers la $4^{\mathrm{e}}$ ou $5^{\mathrm{e}}$ semaine; à ce moment la plante contient jusqu'à $60 \mathrm{mg}$ de 'vitamine $\mathrm{C}$ pour $100 \mathrm{~g}$ de malière fraîche. La plus haute proportion est observée sur des plantes qui renferment $209 \mathrm{mg}$ pour $100 \mathrm{~g}$ de matière sèche. Ce sont les feuilles qui sont les plus riches.

\section{Genre Vigna}

Au Soudan égyptien, la variété de babham du Vigna sinensis mélangée au Sorgho donne un bon ensilage.

\section{VIII. - FAMILLES AUTRES QUE LES GRAMINÉES ET LES LÉGUMINEUSES}

\section{ACANTHACÉES}

\section{Genre Asystosia}

A Magadascar, Asystosia coromandeliana est consommée par les zébus.

\section{AMARANTHACÉES}

\section{Genre Amaranthus}

Amaranthus tristis, que le bétail consomme à Madagascar, renferme en vert 4,24 p. 100 de protéine. La teneur en $\mathrm{Ca}$ (en mg pour $100 \mathrm{~g}$ ) est de 135,5, en phosphore de 101,6.

Les feuilles desséchées d'Amaranthus gangeticus (Inde) ont la composition suivante:

\begin{tabular}{|c|c|}
\hline Eau & 8,77 \\
\hline Protéine ...... & 4,76 \\
\hline Extrait éthéré. & 4,70 \\
\hline Extr. non azoté & 39,17 \\
\hline Cendres & 17,13 \\
\hline $\mathrm{Ca}$ & 3,16 \\
\hline$P$ & 0,8 \\
\hline
\end{tabular}

La teneur en acides aminés, sur la inatière sèche, est de 1 à 2 p. 100: lysine. leucine, isoleucine, arginine, valine; la cystine et la méthionine sont en faible teneur.

Des échantillons peuvent renfermer 10 p. 100 de protéines; la valeur biologique est alors de 67 p. 100 , la digestibilité de 87 p. 100.

\section{AIZOACÉES}

\section{Genre Mesembryanthemum}

Mesembryamthemum croceum et probablement $M$. edvle, roseum, tennifolium, peuvent être utilisés contre l'érosion dans certaines conditions.

\section{AMPÉLIDACÉES}

\section{Genre Ampelocissus}

Les feuilles d'Ampelocissus grantii sont fourragères (Cameroun). La racine a la réputation d'ếtre lactogène

\section{Genre Vitis}

Les feulles de vigne sont riches en vitamine $\mathrm{C}$ : 10 à $20 \mathrm{mg}$ pour $100 \mathrm{~g}$.

\section{ANACARDIACÉES \\ Genre Lannea}

Les feuilles de Lannea humilis sont mangées en saison sèche par les ruminants (Cameroun).

\section{ASCLÉPLADACÉES \\ Genre Leptadenia}

Les tiges et les feuilles de Leptadenia lancifolia sont mangées (Cameroun)

\section{BIGNONIACÉES \\ Genre Kigelia}

Les feuilles de Kigelia aethiopica var. bornuensis, au bord des mares, des rivières, sont volontiers mangées (Cameroun). 


\section{BORAGINACÉES}

\section{Genre Symphitum}

La consoude russe, Symphitum peregrinum, pousse bien en Afrique dans toutes les régions où il ne gèle pas. Au Kenya (altitude $2.300 \mathrm{~m}$ ) on a obtenu $160 \mathrm{t}$./ha de novembre 1954 à juin 1955 d'un champ planté en juillet 54 . On a fait des essais en Afrique du Sud, Nigeria, Gold Coast. Au Kenya, les plantes étaient vertes en avril, alors que tout était desséché. La croissance est rapide; on peut faire 5 à 7 coupes par an, parfois plus. La plante aime les sols profunds, neutres, argileux ou une terre franche, même assez sableuse. On plante en saison des pluies des boutures de racines sur des lignes espacées de $1,20 \mathrm{~m}$ à $1,50 \mathrm{~m}$; on doit arroser. Il faut couper souvent et empêcher la formation de la tige florale. La fumure doit être copieuse: fumier ou nitrate de chaux et potasse.

Les feuilles de $S$. peregrinum ont une teneur élevée en protéine et aussi en potasse. La teneur en cellulose est faible $(9,36$ p. 100 pour la farine de consoude contre 21 p. 100 pour la farine de luzerne) La surface des feuilles porte des poils qui peuvent gêner certains animaux, mais pas les porcs, chèvres et volailles. Pour les autres, on coupe la plante et les poils se fanent aussitôt. Les jeunes feuilles sont aussi utilisées par l'homme.

On peut ensiler ( $1 / 4$ de consoude et $3 / 4$ de mails fourrage) de préférence avec de la mélasse.

Des essais réalisés au cours d'un été chaud et sec, au Natal, ont confirmé les possibilités de Symphytum peregrinum. On a pu couper tous les mois la plante qui sommeille en hiver, commence à pousser en août. De bons résultats ont été obtenus aussi en Uganda, où elle a été utilisée pour la nourriture des Tilapia, au Kenya. En Europe un échantillon a donné 33,68 p. 100 de protéines sur matière sèche; au Kenya, on a oblenu 310 lonnes,heclare pendant la saison de croissance. Il faut, pour cela, fumer de préférence avec une fumure azotée organique. La culture pérenne peut durer 20 ans; les varietés commerciales recommandées sont Webster et Stephenson. Malgré sa richesse en protéine, on peut donner ce fourrage aux ruminants sans risque de météorisation, et aussi aux porcs, chevaux, volailles. Il peut constituer un excellent " mulch " pour lcs arbres fruitiers.

\section{CACTACÉES}

\section{Genre Opuntia}

En Afrique du Sud, les analyses faites à des saisons différentes sur les raquettes de la variété inerme fusicaulis et de la variété chaco montrent qu'il y a dans la composition des différences qui ne tiennent pas seulement à la variété, mais aussi à la saison.

Avec le fusicaulis, la teneur en eau varie de 85,88 p. 100 en été à 90,91 en hiver. Les pourcentages d'éléments sont respectivement:

$\begin{array}{lcc} & E_{\mathfrak{l} \text { été }} & \text { En hiver } \\ \text { Protéine } \ldots \ldots \ldots \ldots \ldots \ldots & 3,07 & 4,45 \\ \text { Extrait éthéré } \ldots \ldots \ldots \ldots \ldots & 1,44 & 1,60 \\ \text { Cellulose } \ldots \ldots \ldots \ldots \ldots \ldots & 10,69 & 12,33 \\ \text { Extr. non azoté } \ldots \ldots \ldots \ldots & 65,28 & 60,82 \\ \text { Cendres } \ldots \ldots \ldots \ldots \ldots \ldots & 19,3 & 20,82\end{array}$

Pour la variété chaco, la teneur en eau était de 89,56 p. 100, la répartition des éléments dans la matière sèche est de:

$\begin{array}{lr}\text { Protéine } \ldots \ldots \ldots \ldots \ldots \ldots \ldots & 3,65 \\ \text { Extr. éthéré } \ldots \ldots \ldots \ldots \ldots \ldots \ldots & 1,49 \\ \text { Cellulose } \ldots \ldots \ldots \ldots \ldots \ldots & 11,98 \\ \text { Extractif non azoté. } \ldots \ldots \ldots \ldots & 63,42 \\ \text { Cendres } \ldots \ldots \ldots \ldots \ldots \ldots \ldots & 19,46\end{array}$

Les raquettes vertes de figuier de Barbarie renferment en Algérie:

$\begin{array}{lr}\text { Epines } \ldots \ldots \ldots \ldots \ldots \ldots \ldots \ldots & 0,44 \\ \text { Eau } \ldots \ldots \ldots \ldots \ldots \ldots \ldots \ldots & 84,26 \\ \text { Proténe brute } \ldots \ldots \ldots \ldots \ldots & 0,73 \\ \text { Extrait éthéré } \ldots \ldots \ldots \ldots \ldots & 0,34 \\ \text { Cellulose } \ldots \ldots \ldots \ldots \ldots \ldots & 2,41 \\ \text { Extractif non azoté } \ldots \ldots \ldots \ldots & 9,04 \\ \text { Matières minérales........... } & 0,73\end{array}$

Sèches, elles renferment:

Epines ................. 2,53

Eau $\ldots \ldots \ldots \ldots \ldots \ldots \ldots . \quad 5,89$

Protéine brute $\ldots \ldots \ldots \ldots \ldots .4,61$

Extrait éthéré ............ 2,24

Cellulose ............... 14,77

Extractif non azoté . . . . . . . 54,26

Matières minérales......... 18,25

La digestibilité est voisine de celle de l'ensilage de mais. Mais on ne peut pas donner plus de 20 à $25 \mathrm{~kg}$ à une vache sans provoquer de diarrhée.

\section{CAPPARIDACÉES}

\section{Genre Capparis}

Au Cameroun, les ruminants mangent les feuilles. et les fruits de Capparis corymbosa, C. decidua, C. tomentosa.

\section{COMMÉLINACÉES}

\section{Genre Commelina}

Commelina nudiflora, hydrophile, est consommée par les zébus, à Madagascar, ainsi que C. Iyallii et C. madagascariensis. 


\section{COMPOSÉES}

\section{Genre Bidens}

Dans certaines régions de Madagascar, Bidens pilosa abonde dans les terres cultivées et est appréciée des bovins.

\section{Genre Conyza}

Plusieurs espèces du genre répandues à Madagascar, dans les terrains de culture, sont appréciées des bovins.

\section{Genre Galinsoga}

A Magadascar, Galinsoga parviflora est consommé par les zébus.

\section{CONVOLVULACÉES}

\section{Genre Ipomoea}

Les fanes d'Ipomoea batatas ont à Madagascar la composition suivante:

\begin{tabular}{|c|c|}
\hline Eau & 81,9 \\
\hline Protides & 1,3 \\
\hline Lipides. . & 0,2 \\
\hline Cellulose & 5 \\
\hline Glucides . & 9 \\
\hline Cendres $\ldots \ldots \ldots \ldots$. & \\
\hline $\mathrm{Ca}$ (mg pour $100 \mathrm{~g}$ ).. & 7 \\
\hline $\mathrm{P} \ldots \ldots \ldots \ldots \ldots$ & 30 \\
\hline
\end{tabular}

Ipomoea reptans qu'on rencontre dans de nombreuses régions marécageuses d'Asie, d'Afrique, d'Océanie, est souvent utilisé dans l'alimentation humaine, mais peu dans l'alimentation animale. Cependant, il mérite mieux en raison de sa teneur en protéine $(28$ à 34,3$)$ pour les feuilles et les pousses, sa faible teneur en cellulose. On le donne en Malaisie aux Iles Fidji au porc et au bétail laitier, de préférence mêlé à Pennisetum purpureum.

Une espèce côtière de Madagascar, I. pescaprae est volontiers mangée par les zébus.

\section{CRUCIFÈRES}

\section{Genre Brassica}

Cultivé au Congo belge, le chou fourrager renferme 9 p. 100 de protéines, 4 p. 100 d'extrait éthéré, 5,8 p. 100 d'extractif non azoté.

\section{CYPÉRACÉES \\ Genre Cyperus}

Cyperus latifolius et $C$. immensus sont des espèces de grande taille dont les hampes florales sont utilisées à Madagascar pour la fabrication de chapeaux, de nattes et que consomment les zébus.

\section{Genre Fuirena}

Dans les rizières inondées de Madagascar, les zébus consomment Fuirena chlorocarpa.

\section{Genure Scirpus}

C'est aussi dans les rizières inondées de Madagascar que les zébus mangent Scirpus joncoides.

\section{EUPHORBIACÉES}

\section{Genre Alchornia}

Au Congo belge, Alchornia yambuyaensis, que le bétail peut ingérer au pâturage avec d'autres plantes, s'y montre toxique.

\section{Genre Fluggea}

Fluggea virosa est un arbuste commun en certaines régions d'Afrique tropicale (Cameroun) dont le bétail mange les feuilles.

\section{LEMNACÉES}

Un certain nombre de plantes aquatiques de cette famille servent à la nourriture naturelle des oiseaux, particulièrement des canards. L'expérience montre qu'on peut les utiliser en sec, pour alimenter des poussins. La teneur en carotène est importante.

\section{LOGANIACÉES}

\section{Genre Strychnos}

Les feuilles de Strychnos spinosa, au Cameroun, sont consommées par les ruminants.

\section{LYTHRACÉES}

\section{Genre Lawsonia}

Les feuilles de Lawsonia inermis sont consommées par le bétail (au Cameroun).

\section{MAUVACEES}

\section{Genre Emilia}

Dans les terrains de culture à Madagascar, les zébus consomment Emilia citrina et $E$. humifusa.

\section{Genre Sida}

A Madagascar, bien que les tiges de Sida rhombifolia soient ligneuses, les zébus mangent volontiers les jeunes pousses.

\section{Genre Urena}

Urena lobata est mangé par les zébus à Madagascar. 


\section{Genre Guazuma}

Des arbres de ce genre entrent dans la formation des bosquets que fréquente le bétail dans les plaines vénézuéliennes. Les animaux mangent volontiers les feuilless de Guazuma tomentosa et $G$. ulmifolia.

\section{MARANTACÉES}

\section{Genre Maranta}

Le canna à fécule, variété fourragère de Maranta arundinacea donne un fourrage dont la composition est la suivante sêlon qu'il est frais ou séché (à Madagascar):

\begin{tabular}{|c|c|c|}
\hline & $\begin{array}{l}\text { Parties aériennes } \\
\text { fraîches }\end{array}$ & $\begin{array}{c}\text { Parties aériennes } \\
\text { séchées }\end{array}$ \\
\hline Eau & $\therefore \quad 87,75$ & 14,54 \\
\hline Protides ........ & 1,59 & 5,62 \\
\hline Lipides & & 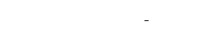 \\
\hline Glucides & 5,55 & 0,30 \\
\hline Cellulose . . . . . . . . . . & 3,37 & 51,34 \\
\hline Cendres $\ldots . . .$. & 1,74 & 10,80 \\
\hline Ca (mg pour $100 \mathrm{~g}$ )... & 17 . & 118 \\
\hline 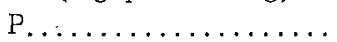 & 24 & 94 \\
\hline
\end{tabular}

\section{PASSIFLORACÉES}

Genre Passiflora

A Madagascar, Passiflora toetida est mangé par les zébus.

\section{PONTEDERIACÉES}

\section{Genre Eichornia}

La jacinthe d'eau, Eichornia crassipes, est devenue un fléau en diverses régions (Indochine, Madagascar, Congo Belge); des îles entières sont envahies; il suffit de quelques semaines à un plant pour donner des milliers de plantes nouvelles. Aucun des moyens de destruction utilisés jusqu'à présent, y compris l'emploi, d'hélicoptères (pulvérisant du chlorexane 80), n'a donné satisfaction entière.

On peut l'utiliser comme engrais et dans l'alimentation. Chez le porc, la plante est donnée fraîche ou cuite avec le mais ou le son; chez le boeuf, ce peut être un bon aliment de saison sèche; fraîche elle est débarrassée des feuilles et des racines, passée a11 hache-paille, mise à fermenter 24 heures après imprégnation d'eau salée, et donnée avec du son.

\section{SALSOLACÉES \\ Genire Kochia}

Kochia trichophylla a la composition suivante:

Matière sèche ........... 21,2

Protéine ................. 15

Extrait éthéré ............ 2,6

Cellulose ............... 24,8

Extractif non azoté ........ 34,8

Cendres ................. 16,8

Kochiz indica, baptisée "herbe allemande " parce qu'elle apparut après l'invasion de l'Egypte par l'Africa Korps, le long des routes, a été volontairement introduite en 1945 et s'est répandue rapidement.

L Institut du désert la considère comme susceptible de permettre la recolonisation des déserts. Sans irrigation, elle a fourni 8,4 tonnes de fourrage par acre (10 aros onv.) et sous irrigation 21 tonnes.

\section{TILIACÉES}

\section{Genre Corchorus}

Les feuilles de Corchorus olitorius sont mangées par les ruminants (Cameroun).

\section{Genre Grewia}

Dans le Nord Cameroun le bétail consomme les feuilles de Grewia cissioides, G. mollis, G. villosa.

\section{IX. - RACINES - TUBERCULES}

\section{COMPOSÉES}

\section{Genre Helianthus}

On a obtenu un hybride de topinambour et de soleil-qui a les qualités des deux espèces, aussi bien en ce qui concerne les tubercules que les " têtes » qu'on peut ensiler.

\section{CONVOLVULACÉES}

Genre Ipomoea

Les patates douces subissent I'influence de la nature du sol et des engrais. Dans tous les types de sol, l'addition d'azote augmente parfois le rendement et, avec le rendement, la teneur en carotène.

$\mathrm{Si}$ le rendement n'est pas modifié ou est diminué, la teneur en carotène ne change pas. Sur certains sols, les engrais phosphatés augmentent rendement et carotène; sur d'autres, non. La potasse augmente le rendement, pas le carotène, sauf si le terrain est argileux. Si on augmente le $\mathrm{pH}$ du sol par la chaux, le carotène augmente.

Dans l'Inde, on envisage de remplacer les variétés blanches de patate douce, qui ne renferment pas 
de carotène, par des variétés à chair orangée qui contiennent de 5,4 à $7,2 \mathrm{mg}$ de carotène pour $100 \mathrm{~g}$ de racine fraîche.

La teneur moyenne de patates douces de Porto Rico en acide ascorbique est de $38,8 \mathrm{mg}$ pour $100 \mathrm{~g}$ de matière fraîche. Elle n'est que de 5,2 chez Caladium colocasia.

Au bout d'un mois de conservation, la perte en vitamine $C$ est d'environ 50 p. 100

L'expérimentation montre que les patates desséchées peuvent avantageusement remplacer l'ensilage dans la ration de vaches laitières qui, par áilleurs, reçoivent du grain et du foin de légumineuses.

\section{EUPHORBIACÉES}

\section{Genre Mahniot}

Les protéines du manioc sont pauvres à la fois én quantité et en qualité, ainsi que l'indique la répartition des acides aminés. Sur 19 de ces éléments, 40 p. 100 de l'azote sont représentés par l'acide glutamique, l'ornithine, l'alanine, l'acide aspartique, la lysine et l'arginine; l'ammoniac, 28 p. 100 et la cystine, la méthionine et le tryptophane 1,5 p. 100.
La farine de tapioca est utilisée parfois pour l'alimentation des volailles, La composition moyenne est :

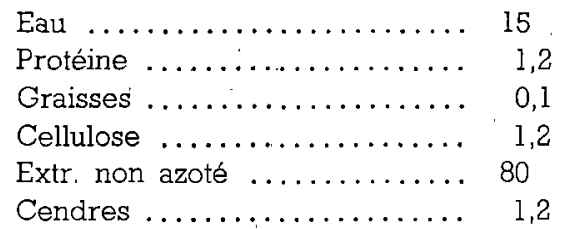

II ne faut pas dépasser 10 p. 100 de la ration; même à ce taux l'utilisation de la ration est plus ou moins réduite:

\section{MARANTACÉES}

Le rhizome du Canna à fécule, variété fourragère de Maranta arundinacea, cultivé à Madagascar; a la composition suivante, selon qu'il est frais (l) ou séché, la plante étant plus mûre (2):

\begin{tabular}{|c|c|c|}
\hline & 1 & 2 \\
\hline Eau & 76,25 & 17,18 \\
\hline Protides & 0,68 & 3,75 \\
\hline Lipides & 0,10 & 0,14 \\
\hline Cellulose. & 1,30 & 1,26 \\
\hline Glucides ... & 20,63 & 75,57 \\
\hline a (mg par $100 \mathrm{~g}) \ldots$ & 9 & 30 \\
\hline$\ldots \ldots \ldots \ldots \ldots \ldots \ldots \ldots \ldots \ldots \ldots$ & 32 & 30 \\
\hline
\end{tabular}

\section{X. - FRUITS - GRAINES}

\section{ANACARDIACÉES}

\section{Genre Spondias}

Les arbres de ce genre ont comme fruits des drupes dont cortaincs sont comostibles: le spondias doux, de Tahiti, répandu en diverses régions tropicales, fournit la « pomme de Cythère » avec laquelle on fabrique des confitures et une boisson fermentée.

Une espèce, l'indian hog plum, Sp. pinnata, dans l'Inde, est couramment mangée. Ie fruit mûr contient 6 à $11 \mathrm{mg}$ d'acide ascorbique pour $100 \mathrm{~g}$ de matière fraîche.

\section{AURANTIÉES}

Les expériences plusieurs fois répétées en Israël paraissent bien montrer que l'alimentation des vaches laitières avec les citrons ou leurs sousproduits amène une augmentation du taux de la matière grasse du lait, augmentation accompagnée parfois d'une diminution, d'autres fois d'une augmentation de la quantité de lait. Quand on supprime cette alimentation le taux de matière grasse redevient normal. Pendant les mois d'hiver, le citron par comparaison avec le fourrage vert, augmente Ia production du lait; au printemps c'est le contraire.

L'huile essentielle mêlée à la ration n'a pas d'influence sur la production laitière; à la dose de $50 \mathrm{~g}$, il y a perte d'appétit.

La pulpe augmente la production laitière de près de $2 \mathrm{~kg}$ par jour et par vache: cela s'explique difficilement, la pulpe étant plus pauvre que l'écorce en éléments nutritifs; d'autre part, si on prolonge cette distribution de pulpe, on cause de l'amaigrissement.

La farine de graines de citron qui renferme 33 p. 100 de protéme, 5 p. 100 de graisse, 8 p. 100 de cellulose cause de la mortalité chez les poussins quand on la substitue au tourteau de soja ou d'arachide: lésions hépatiques, ascite, congestion de l'intestin sont les principales lésions. Les accidents disparaissent avec la farine traitée par l'éther, l'acétone, l'alcool. Il semble que la substance toxique est la limonine, principe amer des graines; mais il pourrait y avoir une deuxième substance.

Les grape-fruits qui ne peuvent êtré livrés ad commerce sont mangés volontiers on Floride par 
le bétail, mieux que les oranges. On fabrique aussi avec les résidus industriels de la pulpe de citron desséchée, de la mélasse de citron, de la farine. La richesse de ces produits en Ca fait qu'il faut ajouter des minéraux pour ajuster le rapport $\mathrm{Ca} / \mathrm{P}$. $\mathrm{Si}$ on ajoute à la mélasse un mélange d'urée à $3 \mathrm{p} .100$ on a une ration qui contient 11 à 12 p. 100 de protéine.

\section{BROMELIACÉES}

\section{Genre Ananas}

Chez des moutons de l'Est africain, les constituants des résidus non pulvérisés d'ananas ont une digestibilité, à peu près nulle en ce qui concerne les protéines et l'extrait éthéré, de 76 p. 100 pour la cellulose et de 80 p. 100 pour l'extractif non azoté.

La composition est la suivante pour 100 de matière sèche:

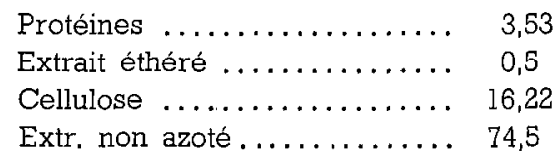

\section{LÉGUMINEUSES}

\section{Généralités}

$\mathrm{Si}$ on compare la valeur nutritive des divers " pois » et « haricots 》 de l'Inde en les incorporant à la ration de façon à constituer 10 p. 100 de protéine, on observe que la plus faible digestibilité est celle de Cajanus indicus, et que la valeur biologique est assez variable: de 41,6 p. 100 pour Lathyrus sativus à 64 p. 100 pour Cicer arietinum, en passant par Phaseolus radiatus, P. mungo, Lens esculenta, Pisum sativum.

Le chauffage à l'autoclave diminue la qualité des protéines chez toutes, sauf Cicer arietinum et Phaseolus mungo.

La composition de divers « pois 》 en acides aminés, offre les différences suivantes: c'est Phaseolus radiatus qui est le plus riche en leucine, isoleucine, valine, histidine, lysine et tryptophane. Cajanus indicus est le plus riche en phénylalanine, phaseolus mungo en méthionine, et Pisum sativum en arginine.

La teneur moyenne de 10 espèces de "pois" et de céréales de l'Inde en tocophérol est, avant germination, ' de $19,9 \mu$.g par gramme. Après 2 à 4 jours de germination, la teneur est respectivement de 223 et 264 p.g par $\mathrm{g}$.

La teneur en riboflavine de « pois 》 divers secs de l'Inde est importante par rapport à celle d'autres aliments: de 1,5 a $3 \mu \mathrm{g}$ par $\mathrm{g}$ pour les racines ne renfermant que 0,5 .
Les différents " pois et haricots » cultivés dans l'Incle causent des accidents quand, chez le rat, on les donne exclusivement ou en grande proportion; la mortalité est importante et beaucoup de sujets présentent de la paralysie; on a incriminé un facteur indéterminé ou la mauvaise qualité des acides aminés, il s'agit plutôt d'une déficience en $\mathrm{Ca}$ et $\mathrm{P}$, puisque l'addition de ces deux éléments à la ration évite les accidents; cela paraît éliminer l'hypothèse selon laquelle agirait une substance inhibitrice de la trypsine, une hémoagglutinine ou encore la teneur en acide cyanhydrique.

$\mathrm{Si}$ on fait germer ces graines (et aussi celles de Cajanus indicus) à l'abri de la lumière directe, il y a augmentation de l'acide nicotinique, de la biotine et de l'acide pantothénique et diminution de l'acide folique.

La teneur comparée de diverses graines américaines, la culture étant faite dans les mêmes conditions de milieu - en acide nicotinique et acide pantothénique est la suivante (moyenne) en $\mu \mathrm{g}$.

$\begin{array}{lcccc} & \text { Blé } & \text { Mais } & \text { Avoine } & \text { Soja } \\ \text { Acide nicotinique } \ldots \ldots \ldots . & 48 & 24 & 14 & 24 \\ \text { Acide pantothénique ...... } & 9 & 6,5 & 15,5 & 25\end{array}$

Quand on incorpore à la ration de rats une bonne proportion de différents 《 pois » et " haricots », de graines de Canavalia et de Stizolobium, on observe toujours un retard dans la croissance; il ne semble pas qu'il y ait une relation constante entre cet effet et la présence d'une substance inhibitrice de la trypsine, une hémoagglutinine ou la teneur en acide cyanhydrique.

\section{Genre Arachis}

Quand on élève des poussins avec une ration dont la protéine est représentée par de la caséine, la croissance se fait mal; elle est améliorée, mais insuffisante, si on ajoute de l'arginine. Mais si on remplace une partie de la caséine par du tourteau d'arachide (15 p. 100) do la ration, la croissance est bien améliorée; de même si on utilise de l'arginine et du tourteau ( $5 \mathrm{p}, 100)$. Il semble ainsi que le tourteau n'assure pas le remplacement d'un acide aminé autre que l'arginine, mais fournit un facteur de croissance inconnu, indispensable aux poussins.

\section{Genre Ceratonia}

A Chypre, pays dégradé par le pâturage nomade, où la température atteint $42^{\circ}$ en saison sèche, avec 350 à $550 \mathrm{~mm}$ de pluie on a adopté une méthode d'aménagement où le caroubier est associé à un pâturage de graminées et de légumineuses. On 
plante dans des trous de 60/60 des plants d'un an, qu'il faut irriguer et pailler la première année. Pour éviter l'embuissonnement, la mise à feu limitée et contrôlée est nécessaire. Le labour est essentiel pour lutter contre les mauvaises herbes.

La plantation revient à 44.000 francs par hectare (66 arbres). Au bout de 20 ans, la production est de $12 \mathrm{~kg}$ de fèves par arbre environ et la prairie (Medicago tribuloides, Lolium rigidum, Phalaris tuberosa, etc.) représente 95 jours de pâturages de mouton par hectare.

Comparée à celle de la farine de poisson, la digestibilité des matières protéiques des graines de caroube, in vitro est nulle alors que celle de la farine de poisson est de 87 p. 100 environ. Quand on mélange les deux produits, la digestibilité de la farine de poisson diminue à mesure qu'augmente la proportion de caroube. Les essais de digestibilité chez le porc donnent des résultats semblables; il ne faut pas dépasser $1 / 10 \mathrm{du}$ poids total de la ration, si on ne veut pas voir diminuer considérablement la digestibilité de l'ensemble des protéines.

\section{Genre Campsiandra}

Ce genre comprend des arbres de l'Amérique tropicale. Au Venezuela, Campsiandra comosa a des gousses qui, quand elles sont mûres, sont recherchées pour la nourriture des porcs. Les Indiens en consomment la farine. Sa composition est la suivante:

$\begin{array}{lrr}\text { Eau } \ldots \ldots \ldots \ldots \ldots \ldots \ldots \ldots \ldots & 15,51 \\ \text { Protéine } \ldots \ldots \ldots \ldots \ldots \ldots \ldots \ldots & 6,68 \\ \text { Extrait éthéré } \ldots \ldots \ldots \ldots \ldots \ldots \ldots & 0,37 \\ \text { Cellulose } \ldots \ldots \ldots \ldots \ldots \ldots \ldots \ldots & 1,34 \\ \text { Extractif non azoté } \ldots \ldots \ldots \ldots \ldots & 75,38\end{array}$

\section{Genre Cicer}

La valeur biologique des protéines de la graine de Cicer arietinum comme d'ailleurs de la graine de Phaseolus mungo augmente après germination.

\section{Genre Clitoria}

Les graines de Clitoria ternatea (Soudan) renferment :

$\begin{array}{lrr}\text { Eau } \ldots \ldots \ldots \ldots \ldots \ldots \ldots \ldots \ldots & 5,68 \\ \text { Graisse } \ldots \ldots \ldots \ldots \ldots \ldots \ldots & 11,76 \\ \text { Protéine } \ldots \ldots \ldots \ldots \ldots \ldots \ldots & 41,19 \\ \text { Cellulose } \ldots \ldots \ldots \ldots \ldots \ldots \ldots & 0,66 \\ \text { Extr. non azoté } \ldots \ldots \ldots \ldots \ldots & 3,48\end{array}$

\section{Genre Entada}

Les graines d'Entada phaseoloides (Soudan) renferment :

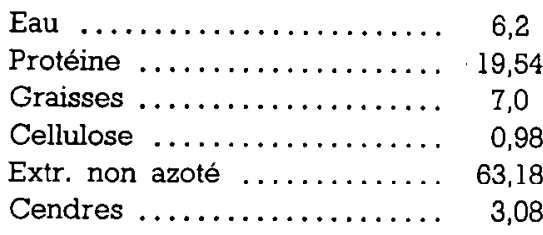

Genre Indigofera

Les graines d'Indigofera glandulosa renferment:

Eau $\ldots \ldots \ldots \ldots \ldots \ldots \ldots \ldots . \ldots \ldots$

Protéine .............. 31,7

Extrait éthéré ........... 4,0

Cellulose ............. 8,1

Extr. non azoté $\ldots \ldots \ldots \ldots \ldots 44,4$

Cendres .............. 3,5

\section{Genre Inga}

Le fruit d'Inga feullei (Pérou) renferme (chiffres arrondis) :

$\begin{array}{ll}\text { Eau } \ldots \ldots \ldots \ldots \ldots \ldots & 83 \quad \text { à } 85 \\ \text { Protéine } \ldots \ldots \ldots \ldots \ldots & 1,83 \text { à } 1,88 \\ \text { Extrait éthéré } \ldots \ldots \ldots \ldots & 1,6 \text { à } 1,9 \\ \text { Cendres } \ldots \ldots \ldots \ldots \ldots & 0,2 \text { à } 1,5 \\ \text { Extr. non azoté } \ldots \ldots \ldots & 9,8 \text { à } 13\end{array}$

Le sol est pauvre en vitamine C: 4 à $9 \mathrm{~m} \mathrm{gp.} 100 \mathrm{~g}$. La vitamine $B_{1}$ existe 0,02 à $0,025 \mathrm{mg} \mathrm{p} .100 \mathrm{~g}$.

\section{Genre Lupinus}

En Afrique du Sud, on a employé la farine de graine de lupin jaune doux, en remplacement intégral de la farine de poisson dans la ration de jeunes porcs à bacon; la substitution ne ralentit pas l'engraissement et ne modifie pas les caractéristiques de la carcasse.

\section{Genre Phaseolus}

Des graines de Phaseolus radiatus de l'Inde, renferment (matière sèche):

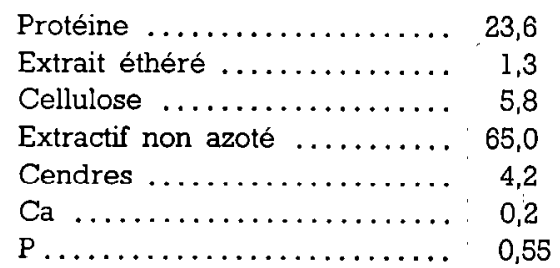

Des essais chez les bovins indigènes montrent que la digestibilité est de $65 \mathrm{p} .100$ pour la matière sèche, 57 p. 100 pour la protéine, 82 p. 100 pour la cellulose, 52 p. 100 pour les graisses, 67 p. 100 pour l'extractif non azoté.

L'alimentation de bovins par une ration composée de paille de riz et, comme aliment concentré, de 
graines' de Phaseolus radiatus (renfermant 23,63 p. 100 de proétine brute et 74,83 p. 100 d'hydrates de carbone) fournit un bilan azoté et un bilan phosphorique positifs, un bilan calcique négatif.

\section{Genre Prosopis}

Prosopis juliflora a un grand succès pour le reboisement des terres arides et dégradées de l'Inde. Le $P$. juliflora arbre, est plus utilisé que le $P$. glandulosa, arbusle. Il pousse rapidement et donne des fruits dès la $3^{e}$ ou $4^{\mathrm{e}}$ année. Une variété donne des fruits deux fois par an; ces gousses sont mangées par tous les animaux, alors que les feuilles ne le sont guère que par les chèvres.

Les gousses de Prosopis juliflora récoltées dans l'Etat de Mysore ont la composition suivante (pour 100 de matière sèche) :

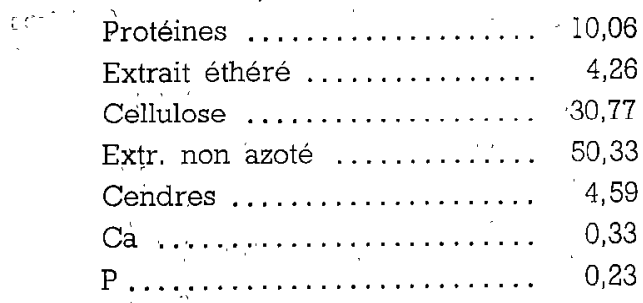

En appliquant aux protéines, à l'extrait éthéré, à la cellulose et à l'extractif non azoté, les pourcentages suivants de matières digestibles: 65, 48,81 et 68 , on obtient les pourcentages suivants de matières digestibles :

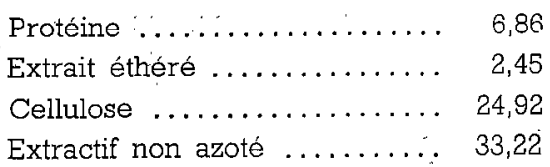

\section{Genre Soja}

Quand on donne à des vaches laitières 5 à $5,5 \mathrm{~kg}$ par jour de graines de soja entières, on n'observe pas d'inconvénients; au-delà, on provoque de la diarrhée. $\mathrm{La}$ production laitière est légèrement augmentée, ainsi que la teneur en matière grasse, avec $2,5 \mathrm{~kg}$; les résultats ne sont pas meilleurs avec des quantités supérieures. Le beurre est plus mou, mais la saveur n'est pas affectée.

La «maladie de Duren » qui n'avait été observée jusqu'alors que chez les bovins, a été récemment rencontrée chez des moutons qui consommaient de la farine de soja dégraissée au trichloréthylène.

Le traitement par l'acide nicotinique permet de sauver un certain nombre de malades.

Le soja non chauffé a aussi une action agglutinante à l'égard des globules rouges de lapin; ce pouvoir agglutinant peut d'ailleurs servir à 'rechercherila température optima de chauffage du tourteau ou de la graine.

Quand on ajoute 1 p. 100 de soyine à une ration qui contient du soja autoclavé, on observe une inhibition marquée de la protéine ou de la caséine. Cette inhibition n'est pas contrariée par la trypsine. On a calculé qu'environ la moitie de l'action inhibitrice 'du soja cru à l'égard de la croissance est due à la soyine, le reste à un effet que peut contrarier la trypsine. D'autres expériences montrent que la diminution de croissance ne peut s'appliquer par l'inhibition de la protéolyse dans le tube digestif.

L'intoxication par le tourteau de soja aux solvants (trichloréthylène) présente une forme aiguë ou chronique. Dans la première on observe de la température, de l'anorexie, une grande faiblesse, du jetage, de l'hyperexcitabilité, des troubles abdominaux, une chute rapide de la lactation. Le jetage contient souvent du sang, et on observe des hémorragies, des hématomes. La miort peut survenir en 5 à 10 jours après l'apparition des symptômes, ou un peu plus tard.

Dans la forme chronique il y a perte progressive de condition, malgré le maintien de l'appétit au 'début; l'affaiblissemont est progressif et finalement on observe de l'ataxie. Le sang offre les lésions d'une anémie aplastique.

Le pouvoir inhibiteur du soja s'adresse surtout, expérimentalement, à la caséine, moins à la peptone ; l'expérience montre aussi quie le chauffagc n'cntraîne pas de changements dans la structure des protéines, mais seulement la destruction du facteur inhibiteur.

Le tourteau de soja par le trichlorethylène cause des accidents que ne "cause pas le tourteau par pression chez le mouton comme chez les bovins. L'acide nicotinamide a un bon effet thérapeutique.

Les propriétés anticoagulantes du tourteau de soja non chauffé sont démontrées expérimentalement chez les porcelets de deux lots, l'un consommant le tourteau non chauffé, l'autre le tourteau autoclavé. Les sujets du premier lot voient leur croissance retardée ainsi que la vitesse de coagulation du sang.

L'addition de vitamine $\mathrm{K}$ n'empêche pas le retard dans la coagulation, ce qui indique que le tourteau n'agit pas en neutralisant la vitamine $K$;

Le tourteau obtenu par solvants renferme des dérivés du groupe isoflavine, genistine et genistéine qui, expérimentalement, ont une activité œstrogène.

Le chauffage à l'autoclave (4 heures à $7 \mathrm{~kg}$ de pression) détruit 30 à 35 p. 100 de la cystine du tourteau de soja. 


\section{Genre Tamarindus}

Les graines décortiquées de Tamarindus indicus renferment:

$\begin{array}{llr}\text { Eau } \ldots \ldots \ldots \ldots \ldots \ldots \ldots \ldots \ldots & 12,0 \\ \text { Protéine brute } \ldots \ldots \ldots \ldots \ldots \ldots & 16,0 \\ \text { Extrait éthéré } \ldots \ldots \ldots \ldots \ldots \ldots \ldots & 6,5 \\ \text { Cellulose } \ldots \ldots \ldots \ldots \ldots \ldots \ldots & 3,8 \\ \text { Cendres } \ldots \ldots \ldots \ldots \ldots \ldots \ldots & 2,8 \\ \text { Extr, non azoté (par différence). } & 58,9\end{array}$

\section{Genre Trigonella}

Les acides aminés existent dans la graine de Trigonella foenum graecum dans les proportions suivantes :

Acide aspartique, 9 ; acide glutamique, 9 ; serine, 6 ; glycine, 9,5; threonine, 5; alanine, 5,9; tyrosine, 3 ; histidine, 1,1 ; lysine, 8 ; arginine, 8 ; phénylalanine, 1 ; leucine, 11; proline, 1; valine + méthionine, 6 .

\section{Genre Vicea}

Une vesce résistante à la sécheresse, Vicia amaena, contient jusqu'à la floraison jusqu'à 2,5 p. 100 d'acide ascorbique dans la matière sèche des feuilles. Toutes les autres parties et notamment les graines sont également riches en vitamine $\mathrm{C}$.

\section{Genre Vigna}

La graine de Vigna sinensis broyée, comparée au tourteau de coton, comme source de protéine dans une ration pour veaux comprenant de l'ensilage de sorgho, du foin de luzerne et du maïs jaune, contient 24,6 p. 100 de protéine contre 42,8 p. 100 pour le tourteau; on remplace ainsi dans la ration quotidienne $1,5 \mathrm{~kg}$ de tourteau par $2,6 \mathrm{~kg}$ de graines. Le taux de croissance est sensiblement le même.

Le facteur limitant, d'après expérience sur le rat, est pour les graines de Vigna sinensis, la méthionine•

\section{MALVACÉES}

\section{Genre Gossypium}

La quantité de tocophérol total pour une tonne de graines de coton varie de 100 à 150 grammes. La quantité de vitamine $E$ varie de 70 à 85 grammes.

Dans le tourteau de graines de coton; les principaux acides aminés sont différemment utilisables. Dans une farine de graines, la lysine ne l'est que dans la proportion de 64 p. 100, alors que la proportion est de 93 p. 100 pour l'arginine, les autres acides aminés étant compris entre ces deux extrêmes. Dans une farine par pression, la méthionine est utilisable dans la proportion de $67 \mathrm{p}$. 100 , et de 82 p. 100 dans la farine de graines. Le résultat est meilleur avec les produits par solvants, le taux étant de 84 à 89 p. 100 pour la lysine.

Le tourteau de graine de coton à plus, de 0,063 p. 100 de gossypol, donné au porc comme source de protéine, gêne la croissance et l'engraissement. L'inconvénient est moindre quand la teneur en gossypol n'est que de 0,024 p. 100; mais même à ce taux les compléments en acides aminés, vitamine $A$ ou vitamine du complexe B sont inactifs.

$L^{\prime}$ extraction par un solvant toxique, le trichloréthylène, n'a pas de consćquence dangereuse, pour les animaux auxquels est distribué le tourteau de coton ainsi traité.

On peut limiter la consommation de tourteau de coton laissé à la libre disposition du bétail en l'additionnant de 25 p. 100 de sel.

Le tourteau de coton privé de gossypol peut constituer sans inconvénient 20 p. 100 de la teneur en protéine dans la ration de volaille en cours de croissance. Il peut remplacer la même proportion de tourteau de soja. Cependant, la combinaison des deux tourteaux a un effet légèrement supérieur, ce qui semble indiquer qu'ils ont une action complémentaire.

La conservation du produit amène la diminution de la teneur en gossypol libre, diminution qui. est plus marquée si on fait passer la température de 37 à $60^{\circ} \mathrm{C}$.

La teneur en gossypol de diverses graines de l'Inde varie entre 0,70 et 0,92 p. 100 alors qu'elle est de 1,9 à 3 p. 100 pour des cotons égyptiens.

La farine de graine de coton provenant du traitement par solvants non chauffée, ou celle qui est faiblement chauffée donnent les meilleurs résultats; le chauffage détruit une partie de la lysine et de la méthionine, ou les rend inutilisables.

L'expérimentation sur le rat montre que la farine de tourteau de coton peut favorablement supplémenter une ration trop pauvre en protéine.

L'expérience montre que le lait de vaches qui consomment du tourteau de graines de coton toxique par sa teneur en gossypol n'a pas d'influence néfaste sur les rats auxquels on donne ce lait.

La digestibilité de l'huile de la graine de coton est très grande, du moins chez l'homme : 95,88 p. 100.

\section{Genre Guazuma}

Guazuma ulmifolia est un arbre des plaines vénézuéliennes, dont le bétail mange volontiers les fruits, comme les feuilles. Le fruit sert d'ailleurs à la fabrication de bière et d'alcool. 
Genre Theobroma

Dans le cacao dégraissé on trouve (pour 1000):

\begin{tabular}{|c|c|}
\hline Theobromine... & 3,35 \\
\hline Caféine $\ldots \ldots \ldots \ldots \ldots \ldots \ldots$ & 0,48 \\
\hline Cendres $\ldots \ldots \ldots \ldots \ldots$. & 5,92 \\
\hline $\mathrm{Ca} O \ldots$ & 0,26 \\
\hline$P O$ & 1,94 \\
\hline
\end{tabular}

\section{MORACÉES}

\section{Genre Artocarpus}

Le fruit d'un arbre à pain, Artocarpus altilis, est communément mangé par les populations des territoires du Pacifique. Frais, il renferme:

\begin{tabular}{|c|c|}
\hline Eau $\ldots \ldots \ldots \ldots \ldots \ldots \ldots$ & 80 \\
\hline Extrait éthéré .... & 0,5 \\
\hline Cellulose $\ldots \ldots \ldots \ldots \ldots \ldots$ & 1,2 \\
\hline$N$ total $\ldots \ldots \ldots \ldots \ldots \ldots \ldots$ & 0,12 \\
\hline Cendres .... & 0,8 \\
\hline Amidon $\ldots \ldots \ldots \ldots \ldots \ldots \ldots$ & 12 \\
\hline$\ldots \ldots \ldots \ldots$ & 0,03 \\
\hline$\ldots$ & 0,03 \\
\hline
\end{tabular}

Les protéines d'Artocarpus integritolius sont assez pauvres en arginine, histidine et méthionine.

\section{MUSACÉES}

La teneur en vitamines de la « peau 》 fraîche de banane est la suivante pour $100 \mathrm{mg}$ de matière sèche:

\begin{tabular}{|c|c|}
\hline Carotène & $1.660 \mu g$ \\
\hline Tocopherol & $3 \mathrm{mg}$ \\
\hline Acid & \\
\hline corbique . & \\
\hline
\end{tabular}

\section{MYRISTICEES \\ Genre Virola}

Au Brésil, une vingtaine d'arbres du genre peuvent fournir plus ou moins de graisses par leurs graines. La meilleure paraît être celle de Virola surinamensis. Les noyaux desséchés (qui constituent 82 p. 100 de la graine) renferment:

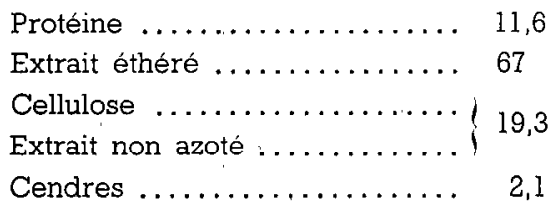

\section{OLÉACÉES}

Les chiffres, dans la composition d'olivos mûres et d'olives vertes sont respectivement les suivants:

\begin{tabular}{|c|c|}
\hline Eau & 69,6 et 78,4 \\
\hline Protéine & et 2,4 \\
\hline Graisses. & et 12,9 \\
\hline s de & et 1,8 \\
\hline end & 3,4 et \\
\hline
\end{tabular}

\section{PALMIERS}

\section{Genre Cocos}

Dans le « lait de coco », de l'apparition du liquide jusqu'à la maturité, les sucres réducteurs croissent jusqu'à 7 mois, atteignant une concentration de 5 p. 100; puis les sucres non réducteurs apparaissent mais vers 12 mois la concentration totale en sucre ne dépasse pas 2 p. 100.

Le « lait 》 de coco comme l'amande, renferme des phosphatases, des hydrogénases, péroxydase et catalase.

\section{Genre Phoenix}

Des dattes du commerce renferment 10 p. 100 de noyaux et 90 p. 100 de pulpe, dans lesquels il $\mathrm{y} a$ :

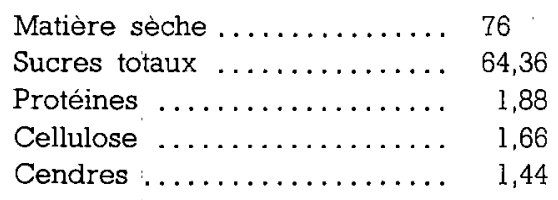

$100 \mathrm{~g}$ de pulpe représentent: 272 calories.

Des dattes avec lesquelles sont faits des essais de digestibilité chez le mouton renferment 78,4 p. 100 de matière sèche ainsi constituée:

Protéine ............. 3,4

Extrait éthéré .......... 1,3

Cellulose.............. 5,8

Extr. non azoté ......... 87,2 (69,8 de sucre) Cendres .............. 2,4

La matière organique a un coefficient de digestibilité de 85,3 p. 100 ; la graisse de 53,1 : l'extractif non azoté, de 92,3 p. 100 . La protéine n'est pas digérée, et la cellulose peu.

Les noyaux broyes renferment 83,7 de matiere sèche, qui contient:

\begin{tabular}{|c|c|}
\hline Protéine & 5,2 \\
\hline Extrait éthéré $\ldots \ldots \ldots \ldots$ & 6,7 \\
\hline Cellulose.............. & 25,7 \\
\hline $\begin{array}{l}\text { Extrait non azote } . . . \ldots \ldots \ldots \\
\text { Cendres }\end{array}$ & 58,9 (15 de sucre) \\
\hline
\end{tabular}

Protéine ............. 5,2

Extrait non azoté ....... 58,9 (15 de sucré)

Cendres ............... 3,5 
Les coefficients de digestibilité sont de 81,4 p. 100 pour la matière organique, 24,9 pour la protéine, 93,5 pour les graisses, 87,4 pour la cellulose, 82,5 pour l'extractif non azoté.

Quant à la pulpe du fruit, 87,7 de matière sèche renferment:

Protéine ............. 6

Extrait éthéré $\ldots \ldots \ldots \ldots \ldots$ 3,1

Cellulose............. 24,9

Extr. non azoté .......... 63 (178 de sucre)

Cendres ............... 3

Les coefficients de digestibilité sont de 65 pour la matière organique, 13,6 pour les protéines, 73,5 pour la cellulose, 68,9 pour la graine, 66,4 pour l'extractif non azoté.

Chez le porc, les noyaux broyés ont un coefficient de digestibilité important pour la cellulose, l'extractif non azoté, moindre pour les graisses, nul pour la protéine.

Si on analyse des dattes (d'Egypte) à leurs divers stades de maturité (de la datte verte à la datte molle) on constate que la matière sèche va de 14,82 à 38,32 p. 100 et les sucres totaux (sur matière sèche) de 42,67 à 84,27 p. 100 ; l'amidon de 11,11 à 2,97 p. 100 , l'extrait éthéré de 2,17 à 3,85 p. 100 , les protéines de 7,77 à 3 p. 100 et les cendres de 3,61 à 2,37 p. 100.

Les dattes de Tunisie renferment en moyenne:

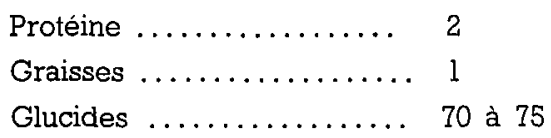

\section{POLYGONACÉES}

Les graines de ragopyrum esculentum, consi dérées comme un bon aliment du porc en Afrique du Sud, y ont la composition moyenne suivante:

$\begin{array}{lr}\text { Matière sèche } \ldots \ldots \ldots \ldots \ldots \ldots \ldots & 88,2 \\ \text { Protéine } \ldots \ldots \ldots \ldots \ldots \ldots \ldots \ldots & 9,9 \\ \text { Extrait éthéré } \ldots \ldots \ldots \ldots \ldots \ldots \ldots & 2,4 \\ \text { Cellulose } \ldots \ldots \ldots \ldots \ldots \ldots & 13,8 \\ \text { Extr. non azoté } \ldots \ldots \ldots \ldots \ldots & 60,2 \\ \text { Cendres } \ldots \ldots \ldots \ldots \ldots \ldots \ldots & 1,8\end{array}$

La graisse est de meilleure qualité qu'avec d'autres farines, mais on peut craindre chez les porcs blancs des accidents de photo-sensibilisation.

\section{SAPOTACÉES}

\section{Genre Lucuma}

Un fruit largement consommé au Pérou, celui de Lucuma obovata contient:

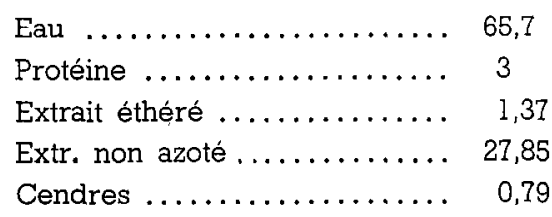

En mg pour 100 il y a: vit. C., 6 mg; vit. Bl, 0,045; riboflavine, 0,131 et carotène 0,065 .

\section{SOLANACÉES}

\section{Genxe Lycopersicum}

La teneur de tomates importées en divers aminoacides est la suivante (ug pour 100 de matière fraîche) :

Acide nicotinique $\ldots \ldots \ldots \ldots \ldots \quad 520$

Acide pantothénique......... 70

Biotine ................. 1

Il n'y a pas de différence marquée entre les variétés exotiques ou indigènes.

\section{XI. - GRAINS}

\section{Généralités}

La teneur en protéine brute de divers "millets " (pour $100 \mathrm{~g}$ de matière sèche) est la suivante (à Ceylan):

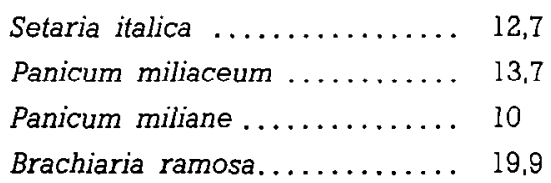

C'est Setaria italica qui est le plus riche en tryptophane.
La teneur comparée de cinq céréales de l'Inde en tryptophane, leucinc, isoleucine et valine (pourcentage sur le produit privé de l'eau et des cendres) est la suivante:

Tryptophone Leucine Isoleucine Voline

$\begin{array}{llllll}\text { Riz ............... } & 0,12 & 0,76 & 0,57 & 0,58 \\ \text { Sorghum vulgare ...... } & 0,11 & 1,12 & 0,53 & 0,52 \\ \text { Eleusine coracana } \ldots \ldots & 0,66 & 0,40 & 0,27 & 0,28 \\ \text { Pennisetum typhoidum . } & 0,25 & 1,25 & 0,77 & 0,82 \\ \text { Blé ................ } & 0,12 & 0,76 & 0,42 & 0,46\end{array}$




\section{Genre Coix}

Tues grains de Coix lacryma jobi obtenus au Congo belge ont la composition suivante:

\begin{tabular}{|c|c|}
\hline Matière sèche & 86,51 \\
\hline Protéines brutes & 10,82 \\
\hline Protéines digestibles & 9,4 \\
\hline Extr & 4,68 \\
\hline Cell & 8,72 \\
\hline lazoté. & 57,71 \\
\hline$\ldots \ldots$ & 4,58 \\
\hline
\end{tabular}

Chez lè porc, la digestibilité des matières grasses et de la cellulose est plus grande que celle des mêmes composants dans' l'orge. On peut, avec un mélange farineux renfermant 30 p. 100 de larmes de Job, réaliser la croissance des porcs jusqu'à l'abattage aussi bien qu'avec un mélange sans Coix. A noter la pauvreté en matières minérales.

\section{Genre Euchleana}

En Amérique centrale, au Mexique, Euchleana mexicana est cultivée pour le bétail. Les graines décortiquées de quatre variétés mexicaines donnent les résultats suivants, en moyenne (pour 100 de graine) :

\begin{tabular}{|c|c|}
\hline Eau & 10 \\
\hline Graisse & 3,17 \\
\hline$N \ldots \ldots \ldots \ldots \ldots$ & 3,48 \\
\hline Methionine ... & 0,49 \\
\hline Lysine & 0,35 \\
\hline Tryptophane. & 0,046 \\
\hline Acide nicotinique & 0,94 \\
\hline
\end{tabular}

La teneur en azote est plus grande que dans la plupart des céréales. La méthionine est deux fois plus abondante que dans le maìs; le tryptophane et la lysine sont en même proportion que dans le mais; l'acide nicotinique est moindre.

\section{Genre Oryza}

L'analyse de trois variétés de paddy de Malaisie donne:

\begin{tabular}{|c|c|c|c|}
\hline Eau & 13,9 & 14,3 & 14,3 \\
\hline Protéine. & 5,7 & 7 & 6,6 \\
\hline Cendres. & 4,8 & 1,21 & 0,69 \\
\hline $\mathrm{Ca}$ & 23,8 & 11,2 & 7.1 \\
\hline$P$ tota & 236 & 262 & 166 \\
\hline Vit. $B_{1}(\mu . g$ par $g)$ & 2,8 & 3,2 & 1,1 \\
\hline
\end{tabular}

Dans le grain de riz, les proportions d'alanine, de thréonine, d'acide glutamique, ainsi que les quantités de lysine et d'histidine diminuent avec l'âge. Il peut arriver que la cystine, absente dans des échantillons jeunes, existe dans des échantillons vieux. Il y a aussi diminution de la vitarnine $B_{1}$.
Quand on obtient du riz poli en enlevant seulement 85 p. 100 de son, le produit obtenu contient assez de vitamine $B_{1}$ pour éviter le béribéri.

La plus grande concentration de la vitamine $B_{1}$ et de la riboflavine du grain de riz se trouve dans l'embryon, la vitamine $B_{1}$ étant surtout dans le scutellum. La vitamine $B_{1}$ se diffuse dans l'endosperme après chauffage précédé de traitement à l'eau chaude ou froide.

L'expérimentation sur le pigeon montre que l'extrait alcoolique de riz poli renferme une substance qui n'est pas à vraiment parler une toxine, mais un antagoniste de la vitamine $B_{1}$.

Les divers traitements qu'on peut faire subir au paddy ont une influence sur la teneur en vitamines.

Du paddy trempé la veille, séché et chauffé de façon à ce que l'enveloppe s'ouvre légèrement, est décortiqué de façon à obtenir 12 à 15 p. 100 de son, puis moulu. La perte en vitamine $B_{1}$ est de 33 p. 100.

\section{Genre Paspalum}

Dans l'Inde, les grains de Paspalum scrobiculatum sont utilisés par les populations pauvres. Comparativement au blé, elle sont pauvres en protéine, $\mathrm{Ca}$ et $\mathrm{P}$.

\section{Genre Setaria}

Des grains de Setaria italica cultivé dans l'Inde renferment décortiquées:

\begin{tabular}{|c|c|}
\hline Eau & 10,7 \\
\hline Protéine & 12,4 \\
\hline Extrait éthéré & 2,2 \\
\hline Cellulose & 0,5 \\
\hline Extr, non azoté & 73 \\
\hline endres ....... & 1,2 \\
\hline
\end{tabular}

Il y a $14 \mathrm{mg}$ de Ca pour 100; 240 de $\mathrm{P}$ et $380 \mu \mathrm{g}$ pour 100 de vit. $B_{1}$.

\section{Genre Sorghum}

Le « Sorgho d'Australie » peut heureusement remplacer le maîs ou l'orge dans la ration des porcs à l'engrais, dans la proportion de 30 p. 100. Si on pousse cette proportion jusqu'à 60 p. 100, le gain de poids est le même, mais la carcasse n'est pas d'aussi bonne qualité.

Si on extrait la prolamine des graines du Sorgho rouge (milo), on détermine par l'analyse que l'azote est, dans le grain et la prolamine, respectivement de 1,864 et 15,61 p. 100 . Quant a la répartition du 
soufre, elle est la suivante dans le grain et la prolamine:

Soufre total ............... 1,825 et 9,761

Soufre: cystine + cystéine ...... 1,477 et 5,248

Soufre: méthionine .......... 0,276 et 1,641

La fabrication d'amidon à partir du grain de sorgho laisse un résidu où domine le gluten, et qu'on distribue notamment aux bovins. La composition moyenne est:

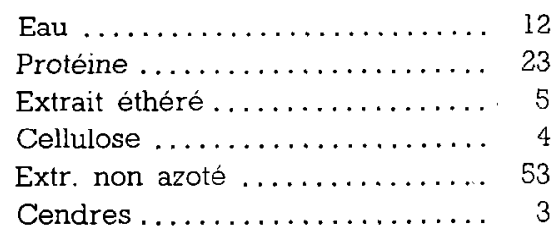

La valeur est sensiblement égale à celle du produit des amidonneries de maïs.

En Australie, quand on remplace tout le blé par du sorgho dans la ration des poussins, on observe une baisse de croissance, le cannibalisme apparait.

\section{Genre Zea}

De façon générale, la constitution génétique du maîs influe notablement sur sa composition chimique et des souches différentes varient notablement au point de vue des éléments nutritifs, mais surtout en ce qui concerne le carotène et les protéines.

Dans des maìs de contenance protéique variable ( 9,9 à 14,3 p. 100 de protéine brute), les différences suivantes sont observées en ce qui concerne les principaux acides aminés et l'acide nicotinique (en $\mathrm{mg}$ ).

\begin{tabular}{|c|c|c|c|c|c|c|}
\hline & & Tryptophone & Lysinc & Máthionine & Cystine & nicotinique \\
\hline & & 8 & 314 & 19 & 144 & 2,53 \\
\hline & 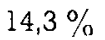 & 99 & 380 & 239 & 182 & 2,40 \\
\hline
\end{tabular}

La proportion de chaque élément par gramme de protéine diminue comme la teneur en protéine augmente. La proportion de zéine augmonte comme augmente le pourcentage de protéine, causant une diminution de la concentration du tryptophane et de la lysine.

Il existe certaines relations entre les protéines, les acides aminés du maîs; la valine, la leucine. l'isoleucine sont dans des proportions plus étroitement liées qu'avec le tryptophane. Quand le pourcentage en zéine daris la protéine totale augmente c'est que la teneur en protéine totale augmente. Comme c'est la zéine qui cause les troubles dans la balance de la protéine, il en résulte que plus le maïs est riche en protéine, plus celle-ci est mal équilibrée.

Quand la protéine augmente, le tryptophane et la valine diminuent et la lysine augmente.

Dans de nombreuses variétés de maïs plus ou moins riches en protéine, on note que l'accroissement des protéines totales ainsi que des constituants, zéine, tryptophane, valine, leucine et isoleucine coincide le plus souvent avec la diminution de la lysine; mais on peut pallier cet inconvénient par la sélection de variétés richas en lysine.

D'autre part, la teneur en acide nicotinique n'est pas en relation avec la teneur en protéines.

Entre les varietés sucrées et les variétés riches en amidon, il y a certaines différences concernant les éléments suivants: tryptophane, acide indolacétique, niacine, hydrates de carbone. Aux stades précédant la maturité, les deuxièmes sont plus riches. A pleine maturité, l'acide indolacétique est semblable, le tryptophane est à peine supérieur.

Diverses recherches montrent que la teneur du maïs en acide nicotinique et en acide panthoténique varie avec le milieu (sol, climat) et avec la variété.

Dans 28 échantillons de maïs (Pérou), la teneur en riboflavine varie de 0,9 à 2,38 $\mu \mathrm{g}$ par gramme.

Dans une variété de maïs qui, contient environ $1,4 \mathrm{mg}$ d'acide nicotinique pour $100 \mathrm{~g}, 63 \mathrm{p} .100$ se trouve dans la couche d'aleurone qui ne représente, en poids que 2,2 p. 100 du grain. Le reste de l'acide nicotinique se trouve dans l'amidon de l'endosperme (20,2 p. 100) qui représente 76,9 p. 100 du grain, et dans le scutellum $(13,1$ p. 100) qui constitue pour 10,6 p. 100 du grair.

Dans une autre variété sucrée qui contient $1,8 \mathrm{mg}$ d'acide nicotinique pour $100 \mathrm{~g}$, l'amidon de l'endosperme renferme deux fois plus de cet élément que dans la variété précédente.

Le tourteau de mais provenant des amidonneries, dans l'Inde, a la composition moyenne suivante:

$\begin{array}{lrr}\text { Fau } \ldots \ldots \ldots \ldots \ldots \ldots \ldots \ldots \ldots & 7,25 \\ \text { Protéines } \ldots \ldots \ldots \ldots \ldots \ldots \ldots & 19,55 \\ \text { Extrait éthéré } \ldots \ldots \ldots \ldots \ldots \ldots & 19,80 \\ \text { Cellulose } \ldots \ldots \ldots \ldots \ldots \ldots \ldots & 7,75 \\ \text { Extractif non azoté } \ldots \ldots \ldots \ldots & 43,13 \\ \text { Cendres } \ldots \ldots \ldots \ldots \ldots \ldots \ldots \ldots & 2,52\end{array}$

Il est plus pauvre en protéine que le tourteau de graines de coton, mais plus riche en matière grasse et en hydrates dc carbono solubles; il est bien assimilé malgré sa richesse en matière grasse.

Quand, dans une ration composée de luzerne et de maïs, on augmente la proportion de mais pour passer de 25 à 50 puis 75 p. 100 de la ration, on observe chez les moutons qui reçoivent ces aliments une augmentation du coefficient de digestibilité de la matière sèche, de la protéine brute, de l'extrait éthéré, de la cellulose et de l'extractif non azoté sauf en ce qui concerne la protéine aux taux de 50 et 75 p. 100 et de la cellulose aux taux de 25 et 50 p. 100 . 